\title{
Analysis of structural relationship among the occupational dysfunction on the psychological problem in healthcare workers: A study using structural equation modeling
}

Mutsumi Teraoka, Makoto Kyougoku

Purpose: The purpose of this study is to demonstrate the hypothetical model based on structural relationship with the occupational dysfunction on psychological problems (stress response, burnout syndrome, and depression) in healthcare workers.

Method: Three cross sectional studies were conducted to assess the following relations: 1) occupational dysfunction on stress response $(n=468), 2)$ occupational dysfunction on burnout syndrome ( $n=1142)$, and 3 ) occupational dysfunction on depression ( $n=687)$. Personal characteristics were collected through a questionnaire (such as age, gender, and job category, opportunities for refreshment, time spent on leisure activities, and work relationships) as well as the Classification and Assessment of Occupational Dysfunction (CAOD). Furthermore, study 1 included the Stress Response Scale-18 (SRS-18), study 2 used the Japanese Burnout Scale (JBS), and study 3 employed the Center for Epidemiological Studies Depression Scale (CES-D). The Kolmogorov-Smirnov test, confirmatory factor analysis (CFA), exploratory factor analysis (EFA), and path analysis of structural equation modeling (SEM) analysis were used in all of the studies. EFA and CFA were used to measure structural validity of four assessments; CAOD, SRS-18, JBS, and CES-D. For examination of a potential covariate, we assessed the correlation of the total and factor score of CAOD and personal factors in all studies. Moreover, direct and indirect effects of occupational dysfunction on stress response (Study 1), burnout syndrome (Study 2), and depression (Study 3) were also analyzed.

Results: In study 1, CAOD had 16 items and 4 factors. In Study 2 and 3, CAOD had 16 items and 5 factors. SRS-18 had 18 items and 3 factors, JBS had 17 items and 3 factors, and CES-D had 20 items and 4 factors. All studies found that there were significant correlations between the CAOD total score and the personal factor that included opportunities for refreshment, time spent on leisure activities, and work relationships $(p<0.01)$. The hypothesis model results suggest that the classification of occupational dysfunction had good fit on the stress response (RMSEA $=0.061, \mathrm{CFI}=0.947$, and $\mathrm{TLI}=$ 0.943 ), burnout syndrome (RMSEA $=0.076, C F I=0.919$, and $\mathrm{TLI}=0.913$ ), and depression (RMSEA $=0.060, \mathrm{CFI}=0.922, \mathrm{TLI}=0.917$ ). Moreover, the detected of covariates include 
opportunities for refreshment, time spent on leisure activities, and work relationships on occupational dysfunction.

Conclusion: Our findings indicate that psychological problems are associated with occupational dysfunction in healthcare worker. Better improvement of occupational dysfunction might be a strategy of better preventive occupational therapies for healthcare workers with psychological problems. However, longitudinal study will be needed in order to judgmental a causal relationship. 
1 Title: Analysis of structural relationship among the occupational dysfunction on the 2 psychological problem in healthcare workers: A study using structural equation modeling 3

4 Authors: Mutsumi Teraoka ${ }^{1,2}$, Makoto Kyougoku ${ }^{3}$

6 Affiliations:

71 Doctor Course, Graduate School of Health Sciences, Kibi International University, Okayama, 8 Japan

92 Oosugi Hospital, Okayama, Japan

103 Department of Occupational Therapy, School of Health Sciences, Kibi International University, 11 Okayama, Japan

\section{Location:}

14 8, Iga-machi, Takahashi City, Okayama, 716-8508, Japan

16 Corresponding Author

17 Name: Mutsumi Teraoka

18 Email: mutsu13t@gmail.com

19 Phone: +81-866-22-9091

21 Competing Interests

22 The authors have declared that no competing interests exist.

\section{Key words}

25 Stress response, Burnout syndrome, Depression, Occupational dysfunction 


\section{Abstract}

28 Purpose: The purpose of this study is to demonstrate the hypothetical model based on structural relationship with the occupational dysfunction on psychological problems (stress response,

30 burnout syndrome, and depression) in healthcare workers.

31 Method: Three cross sectional studies were conducted to assess the following relations: 1) occupational dysfunction on stress response $(n=468), 2)$ occupational dysfunction on burnout syndrome $(\mathrm{n}=1142)$, and 3$)$ occupational dysfunction on depression $(\mathrm{n}=687)$. Personal characteristics were collected through a questionnaire (such as age, gender, and job category, opportunities for refreshment, time spent on leisure activities, and work relationships) as well as the Classification and Assessment of Occupational Dysfunction (CAOD). Furthermore, study 1 included the Stress Response Scale-18 (SRS-18), study 2 used the Japanese Burnout Scale (JBS), and study 3 employed the Center for Epidemiological Studies Depression Scale (CES-D). The Kolmogorov-Smirnov test, confirmatory factor analysis (CFA), exploratory factor analysis (EFA), and path analysis of structural equation modeling (SEM) analysis were used in all of the studies. EFA and CFA were used to measure structural validity of four assessments; CAOD, SRS-18, JBS, and CES-D. For examination of a potential covariate, we assessed the correlation of the total and factor score of CAOD and personal factors in all studies. Moreover, direct and indirect effects of occupational dysfunction on stress response (Study 1), burnout syndrome (Study 2), and depression (Study 3) were also analyzed.

Results: In study 1, CAOD had 16 items and 4 factors. In Study 2 and 3, CAOD had 16 items and 5 factors. SRS-18 had 18 items and 3 factors, JBS had 17 items and 3 factors, and CES-D had 20 items and 4 factors. All studies found that there were significant correlations between the CAOD total score and the personal factor that included opportunities for refreshment, time spent on leisure activities, and work relationships $(\mathrm{p}<0.01)$. The hypothesis model results suggest that the classification of occupational dysfunction had good fit on the stress response (RMSEA = $0.061, \mathrm{CFI}=0.947$, and TLI $=0.943)$, burnout syndrome $(\mathrm{RMSEA}=0.076, \mathrm{CFI}=0.919$, and $\mathrm{TLI}=0.913)$, and depression $(\mathrm{RMSEA}=0.060, \mathrm{CFI}=0.922, \mathrm{TLI}=0.917)$. Moreover, the detected of covariates include opportunities for refreshment, time spent on leisure activities, and work relationships on occupational dysfunction.

56 Conclusion: Our findings indicate that psychological problems are associated with occupational dysfunction in healthcare worker. Better improvement of occupational dysfunction might be a strategy of better preventive occupational therapies for healthcare workers with psychological 
59 problems. However, longitudinal study will be needed in order to judgmental a causal 60 relationship.

61 


\section{Introduction}

63

64

65

66

67

68

69

70

71

72

73

74

75

76

77

78

79

80

81

82

83

84

85

86

87

88

89

90

91

92

Practitioners, educators, and researchers have been acknowledging occupational dysfunction as major health problems in preventive occupational therapy [1-4]. Occupational dysfunction is defined as a negative experience emerging from an unsatisfactory lifestyle atmosphere; it includes occupational imbalance, occupational deprivation, occupational alienation, and occupational marginalization [5,6]. Occupational marginalization is defined as impeding participation in daily activities [7]. Occupational deprivation is a lack of choices in daily activities that are beyond the individual's control [8]. Occupational alienation is the failure to fulfill the inner needs in everyday activities [9]. Occupational imbalance is a loss of balance in engagement during daily activities [10].

Occupational dysfunction occurs not only among the disabled but also in healthy persons $[11,12]$. It has been indicated that occupational dysfunction can occur devoid of apparent medical disease [11]. According to a finding of an observational study of workers without obvious medical disease, $36 \%$ of workers have some occupational dysfunction [13]. Regarding occupational alienation, $43 \%$ of workers from the same study reported experiencing serious psychological problems [13]. Moreover, a report found that occupational dysfunction was observed in $75.4 \%$ of rehabilitation therapists without obvious medical disease, and occupational dysfunction showed a correlation with job stress [14]. People suffering from occupational dysfunction are unable to participate in day-to-day activities of work, leisure, self-care, and rest.

A previous study indicates that healthcare workers frequently experience occupational dysfunction and various psychological issues than other professionals, which includes stress response, burnout syndrome, and depression $[13,14]$. Depression and burnout syndrome are due to an increase in stress response $[15,16]$. Job related stress response is defined as the harmful physical and emotional responses that occur when the requirements of the job do not correlate with the capabilities, resources, or needs of the worker [17]. Job related stress response is recognized as a major psychological issue for healthcare workers [18,19]. Moreover, burnout syndrome is defined as a job related stress response that includes symptoms of exhaustion and indifference toward work [20]. Burnout syndrome influences the job related performance of the healthcare worker to collaborate with other team members under challenging circumstances [21]. At the individual level, burnout syndrome is related to depression for the healthcare worker [22].
Depression is defined as a problem with persistent feelings of sadness and emptiness and a loss 
93 of pleasure and interests [12]. In Japanese society, there is a recognized association between 94 depressive mood and subsequent suicide among workers [23,24]. Furthermore, over 60\% of 95 workers are reported to suffer from a stress related psychological problem in Japan [25]. One of 96 the primary causes of psychological problem among workers is attributed to difficult working 97 conditions, such as heavy overtime work, understaffing, deadline pressure, relationship problems, 98 and cost-cutting practices [26-29]. Many Japanese workers are classified as workaholics, which leads to fatigue and is also one of the causes of depression [29,30]. There has been a growing concern about the psychological problems, especially among healthcare workers, because stress response, burnout syndrome, and depression are the most common work-related health problems in the healthcare profession [31].

However, there has been no previous study examining the impact of classification of occupational dysfunction on psychological problems, including stress response, burnout syndrome, and depression. A case study on occupational therapy has both suggested a causal association between occupational dysfunction and psychological problem [11,12]. A theoretical study on occupational dysfunction has related to mental well-being [32]. Therefore, occupational dysfunction has the possibility to antedate the appearance of psychological problem in workers.

We hypothesize that the occupational dysfunction has the impact of the structural relationship for the stress response, burnout syndrome, and depression of healthcare workers in

111 hospitals (Figure 1). The structural relationship is a snapshot of a point in time and, observed

112 findings suggest to an influence relationship between variables. In Study 1, we hypothesize that 113 occupational dysfunction, as assessed by the Classification and Assessment of Occupational 114 Dysfunction (CAOD), is associated with the Stress Response Scale-18 (SRS-18). In Study 2, we 115 hypothesize that occupational dysfunction is associated with the Japanese Burnout Scale (JBS). 116 In Study 3, we hypothesize that occupational dysfunction is associated with the Center for 117 Epidemiological Studies Depression Scale (CES-D).

118 Moreover, we surmise that occupational dysfunction and psychological problems in

119 healthcare workers is further influenced by personal factors, including age, gender, years of work 120 experience, job category, opportunities for refreshment, time spent on leisure activities, and 121 quality of work relationships.

122 In summary, this study demonstrated the hypothesis model of structural relationship 123 that psychological problems are affected by occupational dysfunction among healthcare workers. 124 


\section{Ethics statement}

126 The Ethics Committee of Kibi International University and the research ethics 127 committee of partnership hospitals approved all research protocol and informed consent 128 procedures (No. 13-30). Written informed consent was obtained from all the participants. We 129 provided participants with a letter explaining the outline and purpose of the study. Participants 130 received the right to drop out of the research project at any time without any reason. We regarded 131 the return of the survey sheet as consent for participation in this research. Survey sheets were 132 returned in anonymous, sealed envelopes.

\section{Statistical software}

SPSS Statistics (http://www.spss.com) were used for the sample characteristics and correlation analysis. Mplus 7.3 (http://www.statmodel.com) was used for the structural equation modeling (SEM) in all studies. The SEM is a comprehensive statistical analysis of the integration

138 of path analysis and factor analysis [33]. SEM aids the identification of structural or cause relationships [33]. Mplus is a statistical modeling software for SEM, developed by Muthén \& Muthén [34].Mplus is a flexible tool to analyze multivariate data [34].

\section{Study 1}

\section{Purpose}

The aim of this study is to test the hypothesis that job related stress response affects occupational dysfunction in healthcare workers (see Figure 1). Moreover, this hypothesis model examines the effect of personal factors on job related stress response and occupational dysfunction.

\section{Methods}

\section{Participants}

In total, there were 468 participants (21 doctors, 159 nurses, 52 physical therapists, 60 occupational therapists, and 176 other healthcare workers). 
154 Measures

155 Sample characteristics: Demographic data were obtained from all participants. We assessed age,

156 gender, job category, years of work experience, opportunities for refreshment, time spent on

157 leisure activities, and work relationships.

158

159 CAOD [6]: We developed CAOD for measuring the classification of occupational dysfunction,

160 based on the Occupation Based Practice 2.0 (OBP2.0) [5,6]. Figure 2 demonstrates that OBP2.0

161 offers a conceptual foundation for the assessment and intervention in occupational dysfunction

162 and belief conflict under various circumstances [6]. Using this model, the occupational therapy

163 practitioner is able to enhance the occupational therapy effects in a person with occupational

164 dysfunction [6]. Furthermore, the occupational therapy practitioner can help the client overcome

165 belief conflicts by using the OBP2.0 [5,35]. Thus, this model will be able to increase the quality

166 of occupational therapy and teamwork. The CAOD measures occupational dysfunction in four

167 domains: occupational marginalization (6 items), occupational imbalance (4 items), occupational

168 alienation ( 3 items), and occupational deprivation ( 3 items). The CAOD comprises 16 items on a

169 7-point Likert scale ( $1=$ strongly disagree, $7=$ strongly agree). CAOD has been widely used as

170 an assessment tool for occupational dysfunction.

171

172 SRS-18 [36]: The SRS-18 was used to measure job related stress response using 18 items in 3

173 subscales: depression and anxiety (6 items), displeasure and anger (6 items), and lassitude (6

174 items $)$ with a 4-point response $(0=$ completely different, $3=$ it's correct $)$. High point totals

175 related to higher degrees of stress.

\section{Statistical analysis}

177 Sample characteristics: The participants' demographics were summarized using descriptive 178 analyses. The normal distribution of all scores was analyzed using the Kolmogorov-Smirnov test $179(\mathrm{p}<0.05)$.

180

181 Structural validity: The factor structure of CAOD and SRS-18 was determined by confirmatory 182 factor analysis (CFA) using a robust weighted least squares factoring method (WLSMV) with 183 missing data [37]. The WLSMV is robust to deviations of data from a hypothetical model and is 184 recommended for structural equation modeling of categorical data with non-normality. Therefore, 
185 we have selected the WLSMV as estimation.

186 We utilized three indexes to evaluate the model data fit of CFA. The first and second 187 indexes were the comparative fit index (CFI) and the Tucker-Lewis index (TLI), with critical 188 values above 0.90 . The third index was the root mean square error of approximation (RMSEA).

189 The diagnostic values of RMSEA from 0.08 to 0.10 indicate a modest fit while less than 0.08 190 indicate a good fit [38].

191 If an unacceptable model fit by CFA was found, we performed an exploratory factor 192 analysis (EFA), utilizing a WLSMV. EFA is able to decide on the appropriate factor structure 193 through reanalysis that even where a poor model fit by CFA was found [38]. EFA also utilizes 194 CFI, TLI, and RMSEA to estimate the model data fit. We reanalysis factor structure of assessment tool by CFA, based on the factor structure supported by the EFA $[38,39]$.

197 Correlation analysis: Correlation analysis was assessed using Spearman's correlation coefficient to measure the association between the factor and total score of CAOD, SRS-18, and the personal factors. The covariates were entered into the path analysis using a correlation analysis technique. Personal factor of more than 0.2 of correlation coefficient against all tools was considered as statistically significant covariates.

202

Structural model: The hypothetical model was analyzed using SEM by WLSMV with missing data. The analysis was examining the structural relationship of occupational dysfunction on the stress response in Figure 1. Personal factors were considered to be covariates that influenced the SRS-18 and CAOD scores. We evaluated the model fit of the hypothesized relationships between latent variables (occupational dysfunction, stress response, and personal factors) and data from SEM. The indirect effects path was stress responses to covariates that include occupational dysfunction.

Model fit index was used the CFI, TLI, and RMSEA. The critical values of RMSEA

211 from 0.08 to 0.10 indicate a mediocre fit, and below 0.08 indicate a good fit. The critical values

212 for CFI and TLI were 0.90 and above. The significance of standardization coefficient were 213 examining by $\mathrm{p}$ value $(\mathrm{p}<0.05)$ and $95 \%$ confidence interval $(95 \% \mathrm{CI})$. This model also 214 estimated the indirect effects path, using Mplus.

\section{Results}


217 Sample characteristics: Sample characteristics are indicated in Table 1. Participants' average 218 age was $35.8(\mathrm{SD}=10.2)$ with a gender distribution of $141(30.1 \%)$ males, $317(67.7 \%)$ females, 219 and $10(2.1 \%)$ others. The Kolmogorov-Smirnov test indicated that all scores had a normal 220 distribution.

221

222 Structural validity of CAOD and SRS-18: Analysis of the CAOD using CFA found that four 223 factors were a good model fit (RMSEA $=0.097$, CFI $=0.963$, and TLI $=0.954)$ in Figure 3. 224 Figure 4 shows the results of the CFA of the SRS-18. The three factors of the SRS-18 were 225 estimated to be a good model fit $(\mathrm{RMSEA}=0.089, \mathrm{CFI}=0.951$, and $\mathrm{TLI}=0.943)$.

227 Correlation analysis: Results are shown in Table 2. Age, gender, job category, and years of 228 work experience had no relation to the CAOD total score and SRS-18. In addition, significant 229 correlation was observed between occupational dysfunction and limited opportunities for 230 refreshment, time spent on leisure activities, and work relationships. These covariates can be 231 understood as a problem of life individual feelings. Therefore, these observable variables have 232 put together in the covariates as latent variable. Table 3 shows the correlation between the factor 233 score of CAOD and SRS-18. The correlation was obtained from all the factors. Therefore, 234 occupational dysfunction and stress response were found to be associated.

236 Structural relationship: Figure 5 and Table 4 shows the model fit indicators for structural 237 relationships. Model fit indicators for the structural model demonstrated of model fit $($ RMSEA = $2380.061, \mathrm{CFI}=0.947$, and TLI $=0.943)$. In this model, occupational dysfunction has structural 239 relationship the stress response (standardized direct effect $=0.748,95 \% \mathrm{CI}=0.500 ; 0.995, \mathrm{p}<$ 240 0.001). Moreover, the covariates (such as opportunities for refreshment, time spent on leisure 241 activities, and work relationships) have structural relationship the occupational dysfunction 242 (standardized direct effect $=0.826,95 \% \mathrm{CI}=0.758 ; 0.894, \mathrm{p}<0.001$ ). However, these 243 covariates were not found to be related to job stress response (standardized direct effect $=-0.062$, $24495 \% \mathrm{CI}=-0.338 ; 0.215, \mathrm{p}=0.566)$. The indirect effects of SRS of the covariates, including 245 occupational dysfunction, was also estimated $=0.617(95 \% \mathrm{CI}=0.396 ; 0.838, \mathrm{p}<0.001)$.

\section{Study 2}


248 Purpose

249

This study aims to test the hypothesis that burnout syndrome is influenced by 250 occupational dysfunction in healthcare workers (see Figure 1). Moreover, this hypothesis model examines the effect of personal factors on burnout syndrome and occupational dysfunction.

\section{Methods}

254 Participants

There were a total of 1142 participants ( 21 doctors, 484 nurses, 205 physical therapists, 256 180 occupational therapists, and 252 other healthcare workers).

Measures

Sample characteristics: Same as Study 1.

CAOD [6]: Same as Study 1.

JBS [40]: The JBS measures burnout syndrome in three domains: depersonalization (6 items; score range 6-30), emotional exhaustion (5 items; score range 1-25), and diminished personal accomplishment (6 items; score range 6-30). The JBS comprises 17 items on a 5-point response scale from 1 (disagree) to 5 (agree).

\section{Statistical analysis} JBS.

271

\section{Results}

273 Sample Characteristics: Table 5 shows the results of sample characteristics. Participant's 274 average age was $34.5 \pm 10.2$ years with a gender distribution of 476 (41.6\%) males, $650(56.9 \%)$ 275 females, and $16(1.4 \%)$ others. The Kolmogorov-Smirnov test showed that all scores were 276 normally distributed.

278 Structural validity of CAOD and JBS: Figure 6 shows the results of CFA of CAOD. First,

279 CFA was found to be a over the criteria of RMSEA of model fit $(\mathrm{RMSEA}=0.102, \mathrm{CFI}=0.951$, 
280

281

282

283

284

285

286

287

288

289

290

291

292

293

294

295

296

297

298

299

300

301

302

303

304

305

306

307

308

309

310

and TLI $=0.940$ ). Therefore, we used EFA with WLSMV. EFA was showed with five factors that included occupational marginalization of shared environment ( 2 items), occupational marginalization of unshared environment (4 items), occupational imbalance (4 items), occupational alienation (3 items), and occupational deprivation (3 items). Therefore, based on EFA, we performed CFA, and found that the CAOD comprised 16 items with 5 factors. The model fit were $\mathrm{RMSEA}=0.089, \mathrm{CFI}=0.965$, and TLI $=0.955$.

Figure 7 shows the results of the CFA of the JBS. The three factors of the JBS were estimated to be a model fit $(\mathrm{RMSEA}=0.091, \mathrm{CFI}=0.963$, and $\mathrm{TLI}=0.956)$.

Correlation analysis: The results are shown in Table 2. Age and years of work experience had no correlation to the CAOD total score or the JBS. Gender and job category of nurses had a weak correlation to JBS. Opportunities for refreshment, time spent on leisure activities, and work relationships fulfilled the criterion correlation. As with study 1, these covariates have analysis using as latent variable. Table 3 shows the correlation between CAOD and JBS. No or only weak correlations were found between Diminished personal accomplishment and CAOD (include occupational imbalance, occupational deprivation, occupational marginalization, and total score).

Structural relationship: Figure 8 and Table 6 shows that the hypothesized model exhibited fit on the first analysis (RMSEA $=0.076, \mathrm{CFI}=0.919$, TLI $=0.913$ ). In this model, occupational dysfunction has structural relationship the burnout syndrome (standardized direct effect $=0.876$, $95 \% \mathrm{CI}=0.723 ; 1.029, \mathrm{p}<0.001$ ). Moreover, some personal factors as covariates (such as opportunities for refreshment, time spent on leisure activities, and work relationships) structural related the occupational dysfunction (standardized direct effect $=0.796,95 \% \mathrm{CI}=0.750 ; 0.841$, $\mathrm{p}<0.001)$. However, the covariates were not found to have a highly significant relation to burnout syndrome (standardized direct effect $=-0.173,95 \% \mathrm{CI}=-0.349 ; 0.003, \mathrm{p}=0.011$ ). Indirect effects of JBS to covariates includes occupational dysfunction was estimated $=0.697$ $(95 \% \mathrm{CI}=0.556 ; 0.838, \mathrm{p}<0.001)$.

\section{Study 3}

\section{Purpose}


312 dysfunction in healthcare workers (see Figure 1). Moreover, this hypothesis model examines the

313 effect of personal factors on depression and occupational dysfunction.

314

315 Methods

316 Participants

317 In this study, a total of 687 participants were included: 401 nurses (including 12 public

318 health nurses and midwives and 63 assistant nurses), 155 physical therapists, 123 occupational

319 therapists, and 8 other healthcare workers.

320

321

Measures

322 Sample Characteristics: Same as Study 1 and 2.

323

324 CAOD [6]: Same as Study 1 and 2.

325

326 CES-D [41]: CES-D was measured based on the level of depression experienced within the past 327 week using 20 items on 4 subscales: depressed affect (7 items), negative affect (4 items), 328 interpersonal difficulties ( 2 items), and somatic symptoms (7 items). Questions were answered 329 using a 4-point response $(0=$ never, $3=$ all the time $)$. In epidemiologic studies, CES-D has been 330 used worldwide as an assessment tool for depression. Among the negative affect-related items, 4 331 were originally regarded as related to a positive affect. In the present study, the 4 items were 332 inversely scored to make this point more comprehensible.

333

334 Statistical analysis

335

336

Statistical analysis is the same as Study 1. Measurement tools to be used CAOD and

337

\section{Results}

339 Sample Characteristics: Table 7 indicates the results of sample characteristics, including 159

340 males, 509 females, and 7 unknowns, with an average age of $33.6 \pm 10.2$ years. The

341 Kolmogorov-Smirnov test showed that all scores had normal distribution. 
343 Structural validity of CAOD and CES-D: Figure 9 shows the results of the CFA on CAOD.

344 Firstly, the CFA was found to have a poor estimate of RMSEA for model fit (RMSEA $=0.104$, $345 \mathrm{CFI}=0.943$, and TLI $=0.931)$. Therefore, we performed EFA, and found that the CAOD 346 comprised 16 items of 5 factors like study 2.The indexes for the EFA model were RMSEA = $3470.066, \mathrm{CFI}=0.988$, and TLI $=0.972$. Based on EFA, CFA of CAOD was determined to be a $348 \operatorname{good}$ estimate of model fit $(\mathrm{RMSEA}=0.092, \mathrm{CFI}=0.958, \mathrm{TLI}=0.946)$.

Figure 10 shows the results of a CFA of CES-D. The CFA model for the latent factors 350 of CES-D exhibited good fit for depressed affect, negative affect, interpersonal difficulties, and somatic symptoms $(\mathrm{RMSEA}=0.060, \mathrm{CFI}=0.950$, and $\mathrm{TLI}=0.942)$.

352

353 Correlation analysis: The results are shown in Table 2. Age, gender, job category, and years of

354 work experience had no correlation to the CAOD total scores. Opportunities for refreshment, 355 time spent on leisure activities, and work relationships fulfilled a criterion correlation. As with 356 study 1 and 2, these covariates have analysis using as latent variable. Table 3 shows the correlation between CAOD and CES-D. Correlation was obtained from all the factors; occupational dysfunction and depression were found to be associated.

359

360

Structural relationship: Figure 11 and Table 8 demonstrates the results of the final model. The hypothesized model exhibited model fit $(\mathrm{RMSEA}=0.060, \mathrm{CFI}=0.922$, TLI $=0.917)$. In this model, occupational dysfunction has structural relationship the depression (standardized indirect effect $=0.695, \mathrm{p}<0.001,95 \% \mathrm{CI}=0.521 ; 0.869)$. Moreover, personal factors as covariates (such as opportunities for refreshment, time spent on leisure activities, and work relationships) have structural relationship the occupational dysfunction (standardized direct effect $=0.796$, $95 \% \mathrm{CI}=0.750 ; 0.841, \mathrm{p}<0.001)$. Furthermore, covariates were not related to the burnout syndrome (standardized direct effect $=0.063,95 \% \mathrm{CI}=-0.133 ; 0.259, \mathrm{p}=0.407$ ). Indirect effects of CES-D to covariates including occupational dysfunction were also estimated $=0.544$ $(95 \% \mathrm{CI}=0.398 ; 0.690, \mathrm{p}<0.001)$.

\section{Discussion}

This study was aimed to identify by a hypothetical model of a structural relationship 373 that psychological problems are affected by occupational dysfunction in healthcare workers 
374 (Figure 1). Our biggest finding was confirming the structural relationship, indicating that 375 hypothesis model was valid across three studies.

376 Our three studies showed that occupational dysfunction has a significant role on 377 psychological problems; it includes stress, burnout, and depression. The result of the study was 378 the displayed that CAOD factor scores were significantly and positively correlated with SRS-18, 379 JBS, and CES-D total scores (Table 3). Moreover, even after making the necessary amendments 380 to the covariance (limited opportunities for refreshment, time spent on leisure activities, and 381 work relationships), psychological problem in healthcare worker was explained by occupational 382 dysfunction (Figures 5, 8 and 11, Tables 4, 6 and 8). This finding is significant because a 383 majority of research studies on occupational dysfunction has focused on prevalence rate based on 384 epidemiological observational study $[13,14]$.

385 In the cross sectional design, it is difficult to posit about cause/effect; however our 386 results suggest that occupational dysfunction is an important factor in building psychological 387 problem. Occupation is the centered of the human experience in everyday life; it includes things 388 people need to do, want to do, and are expected to do [32]. The concept of occupational 389 dysfunction is a negative human experience to occur by a lifestyle issue [6]. A healthy lifestyle is 390 an essential to psychological problem reduction [12]. In other words, people have the potential to 391 promote the psychological problem by occupational dysfunction of a lifestyle issue [32]. In this 392 respect, the present findings suggest by statistical evidence that occupational dysfunction and 393 psychological problem have revealed a significant structural relationship.

This study indicated that all measurement tools were significantly and positively correlated with opportunities for refreshment, time spent on leisure activities, and work relationships in personal factors (Table 2). Meanwhile, the path analysis of three studies indicated that CAOD was only significantly and positively related with these personal factors

398 (Figures 5, 8 and 11, Tables 4, 6 and 8). In addition, no or only weak correlations were found 399 between all measurement tools and other personal factors (age, gender, job category, and years 400 of work experience) in this study (Table 2). Therefore, we considered that behind the 401 occupational dysfunction is holding a problem of human relations, unbalance of the lifestyle in 402 this study.

CFA approach displayed good fitness levels. We were able to understand of the 404 objective phenomenon the using the factor structure of all measurement tools. However, the 405 factor structure of occupational marginalization of the CAOD differed from among the three 
406 studies. Study 1 and previous study [6] was the same factor structure such as occupational 407 marginalization. On the other hand, Studies 2 and 3 were vary factor structure; it shared and non408 shared environmental occupational marginalization. However, the shared and non-shared 409 environmental occupational marginalization stems from the concept of occupational 410 marginalization. Therefore, CAOD factor structure of study 1 is not irrelevant to it of studies 2 411 and 3 . We think that result of CAOD of three studies can understand as the framework in a 412 similar occupational marginalization.

413

\section{2. Clinical usefulness}

415 CAOD is an assessment tool that has been developed as a theoretical background the 416 OBP2.0. This is able to intervention for people with disabilities but also healthy people. We can 417 consider intervention to healthcare workers with occupational dysfunction by reveals structural 418 relation of occupational dysfunction and psychological problems. For example, healthcare 419 workers could be routinely asked to answer the CAOD to identify their existing classification of 420 occupational dysfunction. Subsequently, an occupational therapist or occupational health 421 physician could meet with each healthcare worker to review the responses and gain a clear 422 understanding of their occupational dysfunctions. Some of the methods for solution with 423 occupational dysfunction include occupational therapy, psychological therapy, and cognitive 424 behavioral therapy. Effective application of these approaches could help healthcare workers with 425 occupational dysfunction.

426

427

\section{Limitation}

Our study has several limitations. First, this study was cross-sectional design. However, this design was appropriate because a previous study was not investigated the relationships between the occupational dysfunction and psychological problem; it includes stress response,

431 burnout syndrome, and depression. For the future, longitudinal studies are needed to the causal 432 relationship of the existence of occupational dysfunction related psychological problem. Second, 433 all participants were recruited from among healthcare worker in Japan. This may be limiting the 434 possibility to generalization these findings to the other population. Third, our study is using selfreport assessments; it includes CAOD, SRS-18, JBS and CES-D. There instruments has high validity. However, we need to use observation assessment together for accurate diagnostic. 
438 Figures

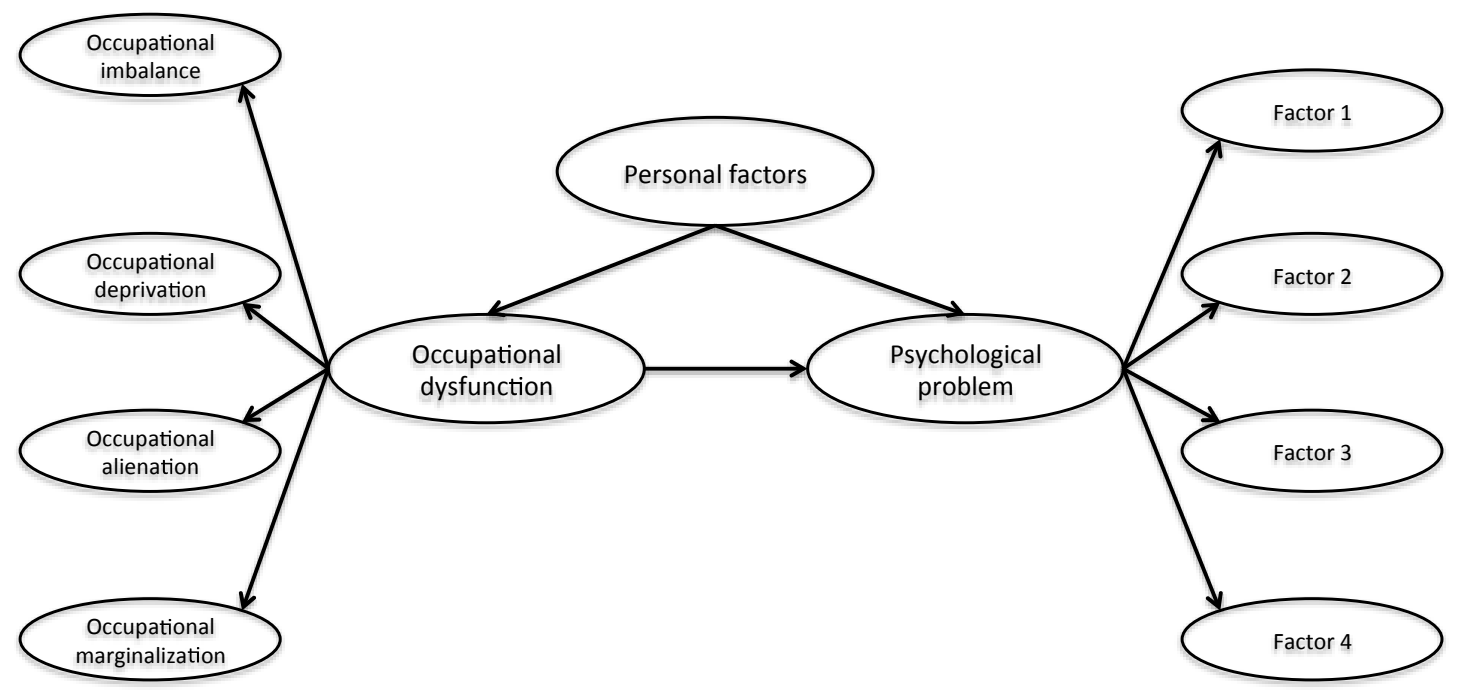

\section{Figure 1. The hypothesized model of structural relationship}

441 Note. Occupational dysfunction includes occupational imbalance, occupational deprivation, 442 occupational alienation, and occupational marginalization. Psychological problems include stress 443 response (Study1), burnout syndrome (Study2), and depression (Study3). The purpose of three 444 studies are to examine whether the hypothesis model can be reproduced. Personal factors include 445 age, gender, years of work experience, job category, opportunities for refreshment, time spent on 446 leisure activities, and work relationships. 


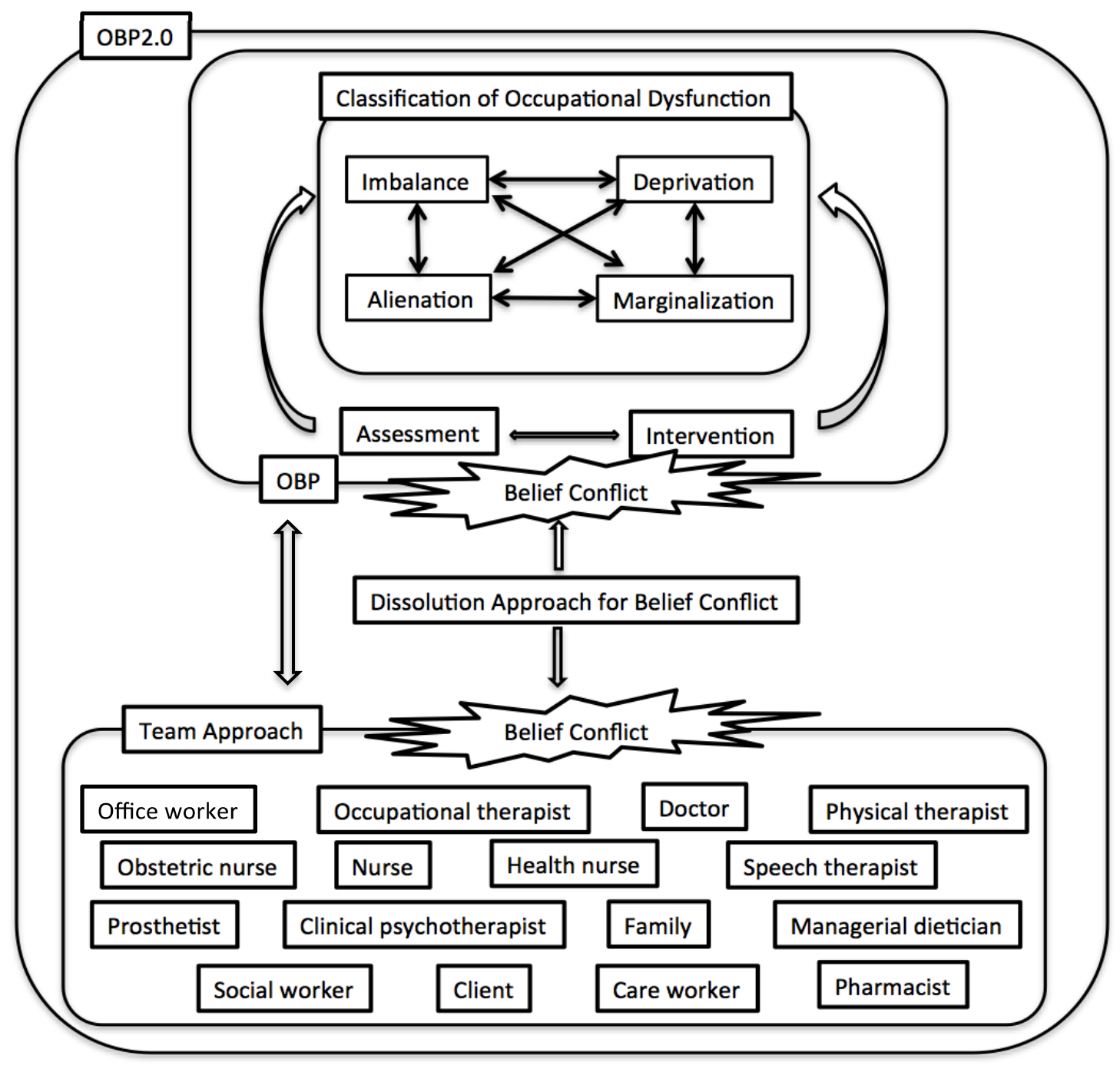

451 Figure 2. Occupation based practice 2.0 (OBP2.0) model

452 Note. Description of theoretical structure of the OBP2.0. The purpose of this model is to

453 improving of occupational dysfunction and promoting of teamwork. The improving of

454 occupational dysfunction has used assessment and intervention of an occupation based practice

455 (OBP). OBP is occupational therapy technique to increase with health and well-being through a 456 meaningful occupation. In addition, using this model, the promoting of teamwork has used the 457 Dissolution Approach for Belief Conflict (DAB) [42]. DAB is intervention technique for 458 dissolving the dissensus. OBP2.0 is able to use for improve the both occupational dysfunction 459 and belief conflict. 


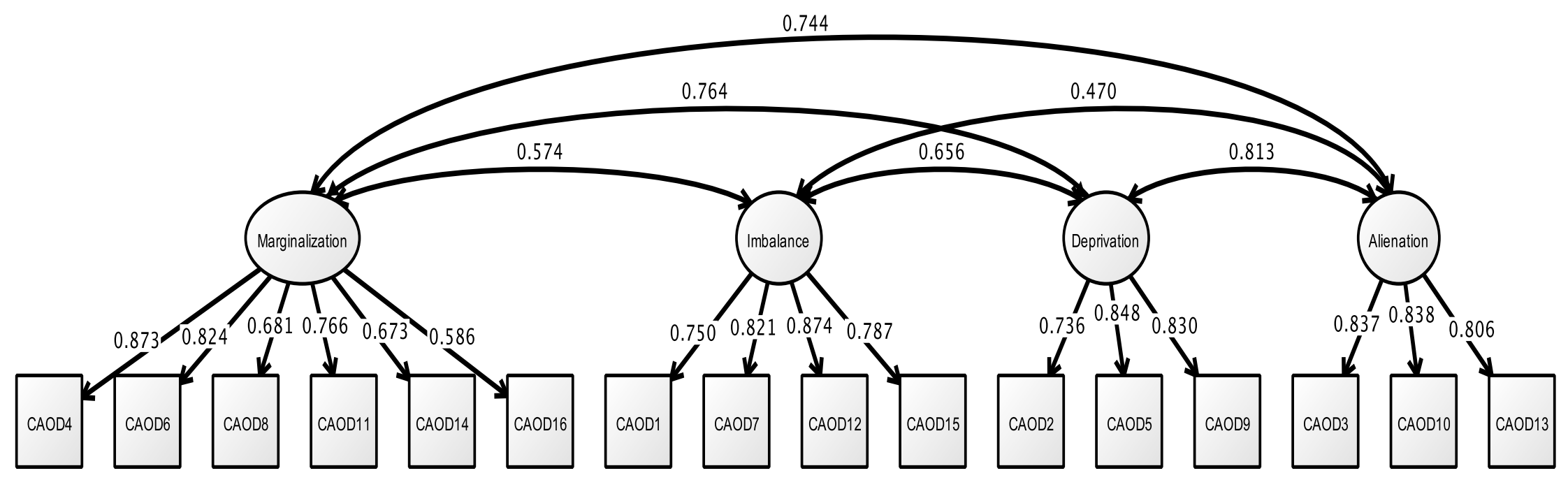

461

\section{Figure 3. CFA of CAOD (study 1)}

Note. Marginalization $=$ Occupational marginalization, Imbalance $=$ Occupational imbalance, Deprivation $=$ Occupational deprivation, 


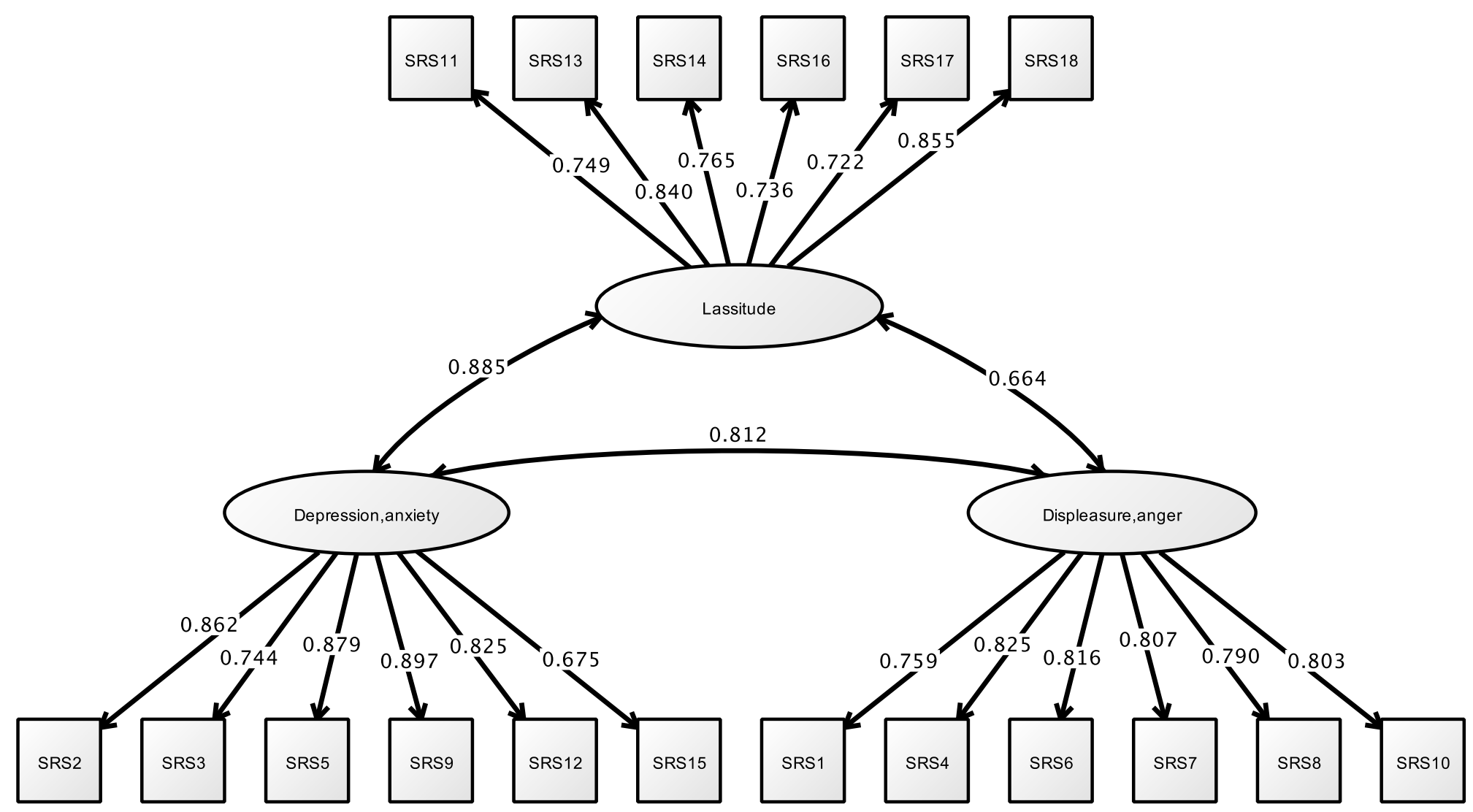

Figure 4. CFA of SRS-18 (study 1)

470 Note. Previous study showed the depression and anxiety (SRS2, 3, 5, 9, 12, 15), displeasure and anger (SRS1, 4, 6, 7, 8, 10), and

471 lassitude (SRS11, 13, 14, 16, 17, 18). RMSEA $=0.089, \mathrm{CFI}=0.951, \mathrm{TLI}=0.943$ 


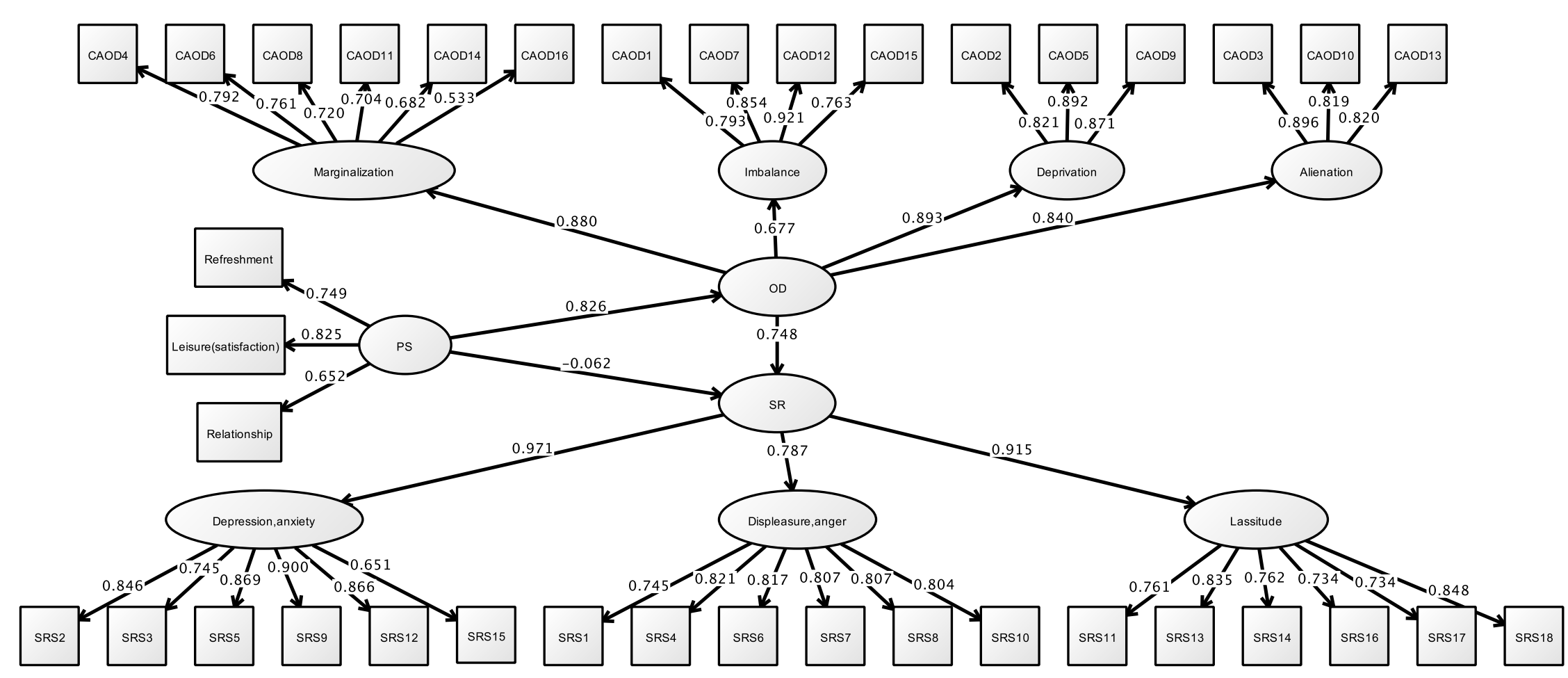

\section{Figure 5. Structural relationships of SRS-18 on CAOD (study 1)}

Note. OD = Occupational dysfunction, PS = Personal factor, SR $=$ Stress response, Refreshment $=$ Opportunities for refreshment,

Leisure $($ satisfaction $)=$ Time spent on leisure activities, Relationship $=$ Work relationships. RMSEA $=0.061$, CFI $=0.947$, TLI $=$ 


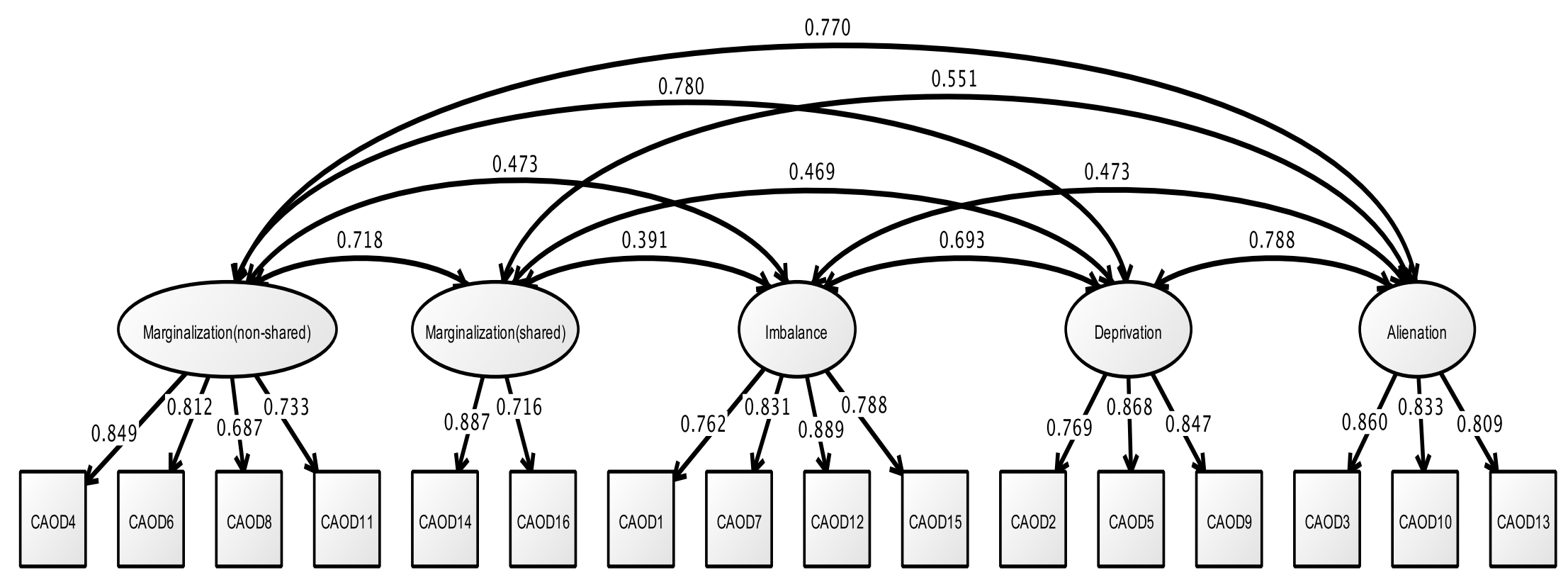

\section{Figure 6. CFA of CAOD (study 2)}

Note. Marginalization (non-shared) $=$ non-shared environmental occupational marginalization, Marginalization $($ shared $)=$ shared $\mathrm{CFI}=0.965, \mathrm{TLI}=0.955$ 


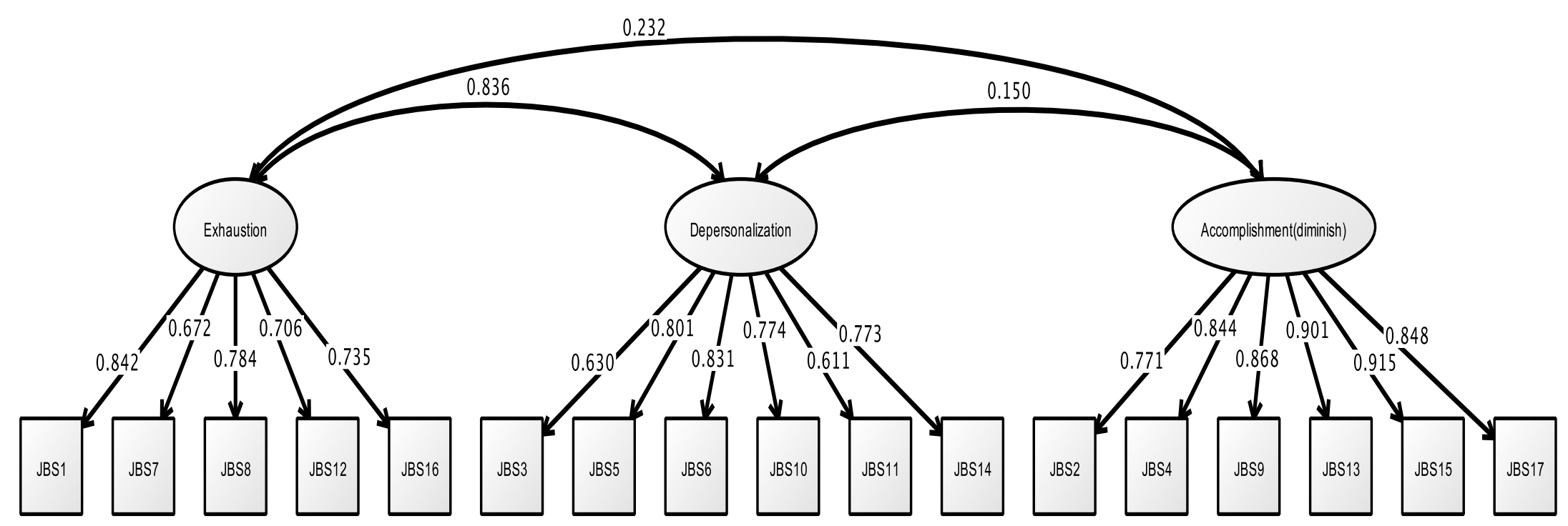

\section{Figure 7. CFA of JBS (study 2)}

Note. Exhaustion $=$ Emotional exhaustion, Accomplishment $($ diminish $)=$ Diminished personal accomplishment. Previous study 


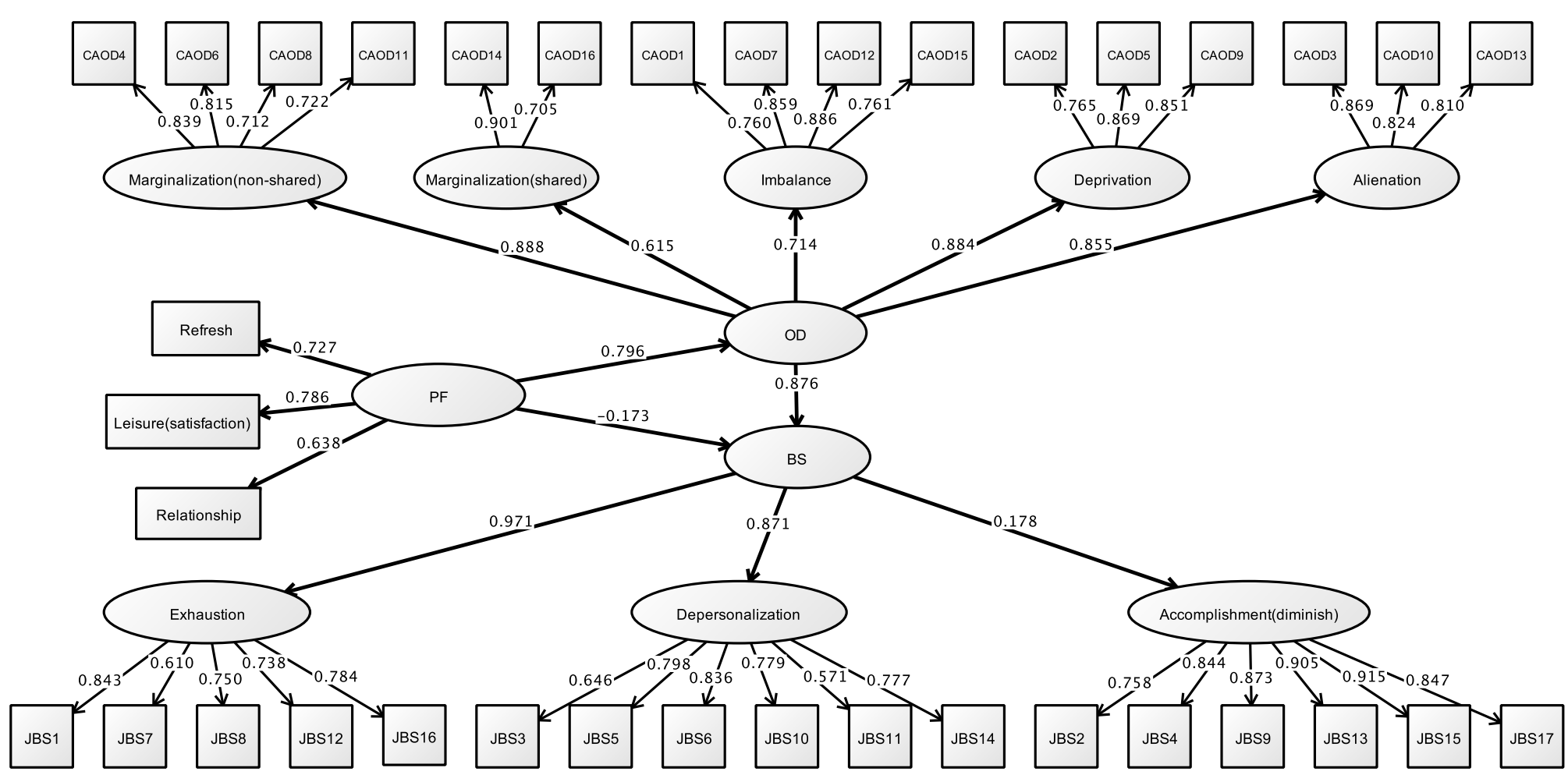

490 Figure 8. Structural relationships of JBS on CAOD (study 2)

491 Note. $\mathrm{OD}=$ Occupational dysfunction, $\mathrm{BS}=$ Burnout syndrome. Another latent variables name are same as Study $1 . \mathrm{RMSEA}=0.076$, $492 \mathrm{CFI}=0.919, \mathrm{TLI}=0.913$ 


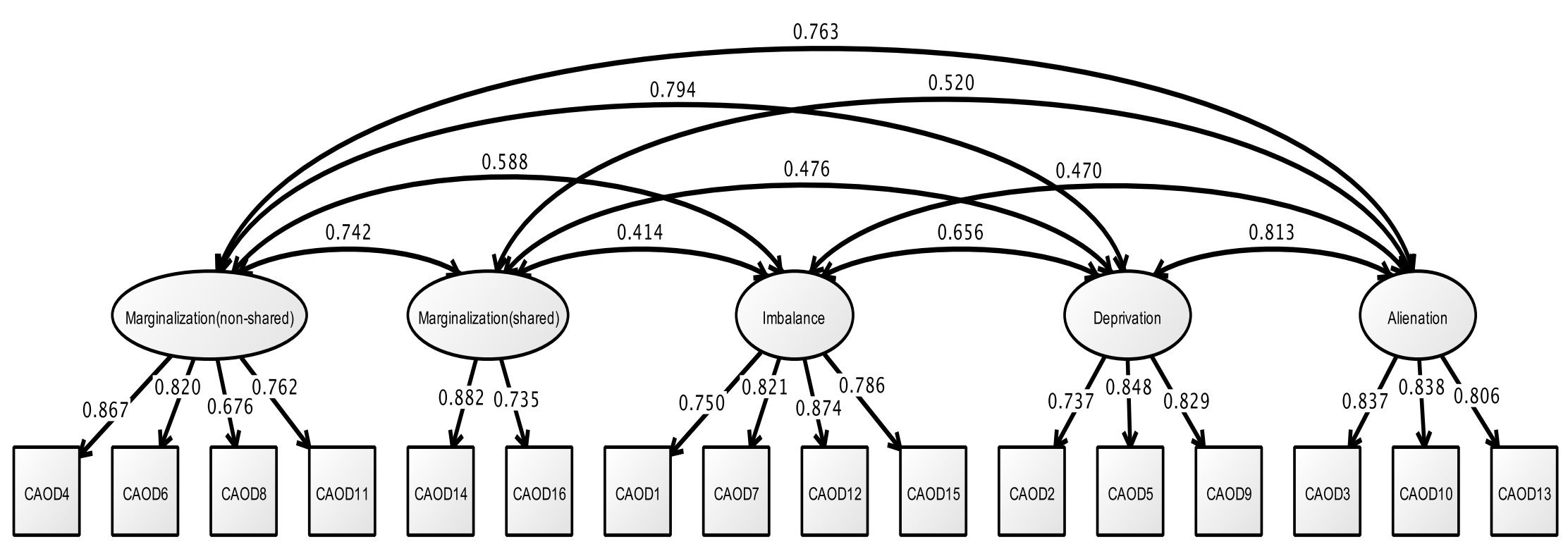

\section{Figure 9. CFA of CAOD (study 3)}

495 Note. Latent variables name and factor structure are same as study 2. RMSEA $=0.092, \mathrm{CFI}=0.958, \mathrm{TLI}=0.946$ 


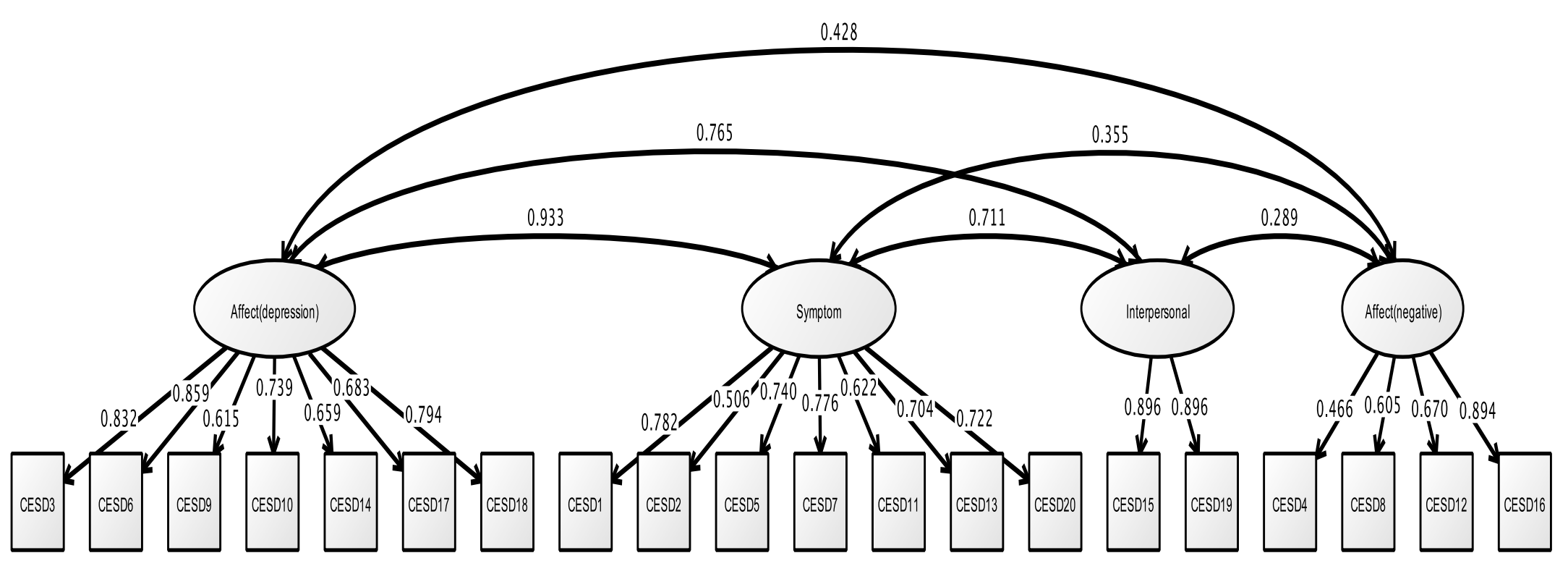

497

\section{Figure 10. CFA of CESD (study 3)}

499 Note. Affect $($ depression$)=$ Depressed affect, Symptom = Somatic symptoms, Interpersonal = Interpersonal difficulties, Affect

500 (negative) $=$ Negative affect. Previous study showed the depressed affect (CESD3, 6, 9, 10, 14, 17, 18), somatic symptoms (CESD1, 2,

$5015,7,11,13,20)$, interpersonal difficulties (CESD15, 19), and negative affect (CESD4, 8, 12, 16). RMSEA =0.060, CFI =0.950, TLI $502=0.942$ 


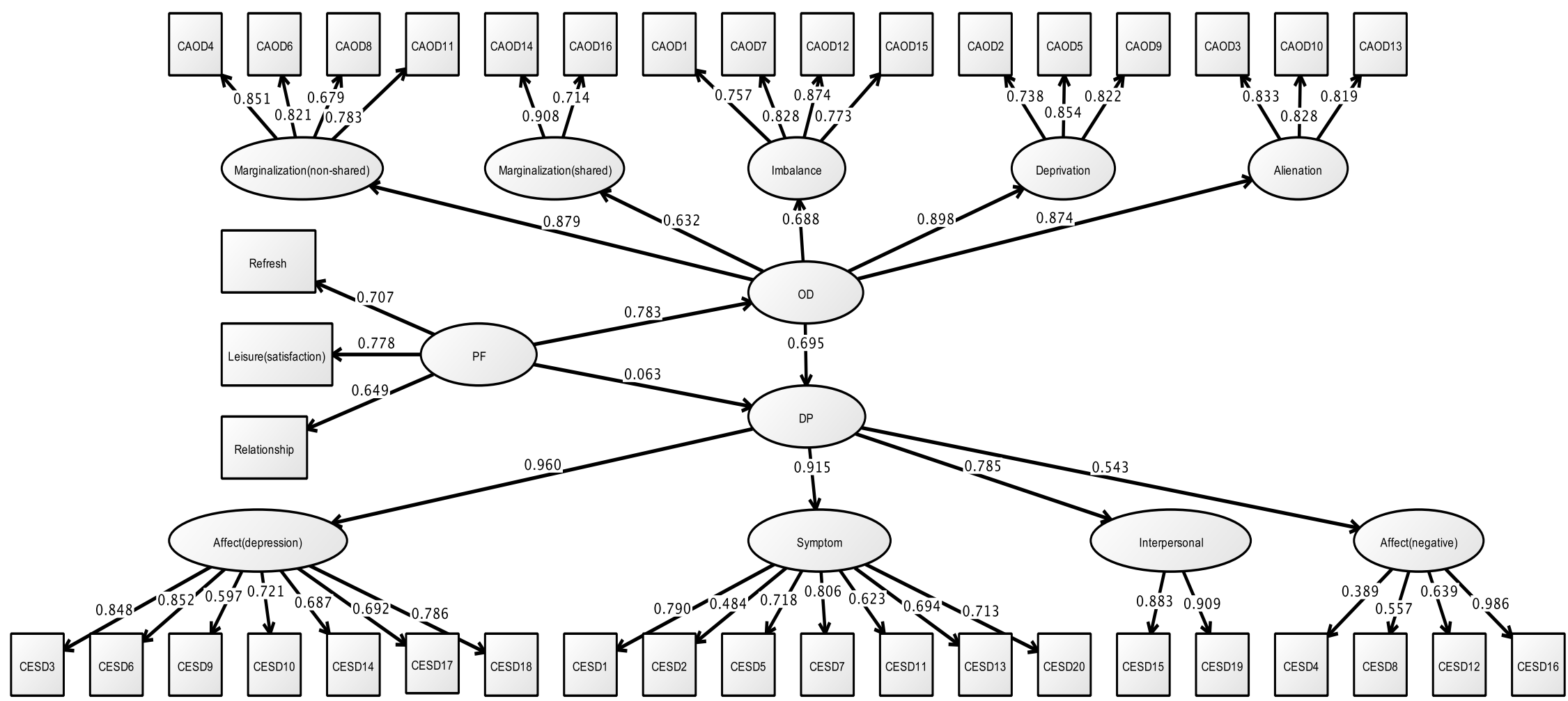

11. Structural relationships of CES-D on CAOD (study 3 )

505 Note. $\mathrm{DP}=$ Depression. Another latent variables name are same as Study 1 and 2. RMSEA $=0.060, \mathrm{CFI}=0.922, \mathrm{TLI}=0.917$ 
506 Table 1. Sample characteristics of CAOD and SRS-18 (study 1)

\begin{tabular}{|c|c|c|c|}
\hline & & \multicolumn{2}{|c|}{$\mathbf{M} \pm \mathbf{S D}$} \\
\hline \multirow{6}{*}{ Age } & Total & \multicolumn{2}{|c|}{$35.8 \pm 10.2$} \\
\hline & Doctors & \multicolumn{2}{|c|}{$48.6 \pm 10.2$} \\
\hline & Nurses & \multicolumn{2}{|c|}{$36.1 \pm 10.8$} \\
\hline & Physical therapists & \multicolumn{2}{|c|}{$34.4 \pm 8.5$} \\
\hline & Occupational therapists & \multicolumn{2}{|c|}{$33.7 \pm 8.3$} \\
\hline & Others & \multicolumn{2}{|c|}{$34.9 \pm 9.3$} \\
\hline & Total & \multicolumn{2}{|c|}{$11.8 \pm 9.4$} \\
\hline & Doctors & \multicolumn{2}{|c|}{$23.3 \pm 10.0$} \\
\hline Years of work & Nurses & \multicolumn{2}{|c|}{$13.5 \pm 10.2$} \\
\hline experience & Physical therapists & \multicolumn{2}{|c|}{$10.9 \pm 7.6$} \\
\hline & Occupational therapists & \multicolumn{2}{|c|}{$9.62 \pm 7.7$} \\
\hline & Others & \multicolumn{2}{|c|}{$9.68 \pm 8.3$} \\
\hline & & Total N & $\%$ \\
\hline \multirow{3}{*}{ Gender } & Male & 141 & 30.1 \\
\hline & Female & 317 & 67.7 \\
\hline & Others & 10 & 2.1 \\
\hline \multirow{5}{*}{ Job category } & Doctor & 21 & 4.5 \\
\hline & $\begin{array}{lll}\text { Nurse, } & \text { Health nurse, } \\
\text { Midwife } & & \end{array}$ & 159 & 34.0 \\
\hline & Physical therapist & 52 & 11.1 \\
\hline & Occupational therapist & 60 & 12.8 \\
\hline & Other healthcare workers & 176 & 37.6 \\
\hline \multirow{6}{*}{$\begin{array}{l}\text { Opportunities } \\
\text { for refreshment }\end{array}$} & Very good & 41 & 8.7 \\
\hline & Good & 265 & 56.6 \\
\hline & Neither good nor bad & 52 & 11.1 \\
\hline & Fair & 56 & 11.9 \\
\hline & Poor & 44 & 9.4 \\
\hline & Unknown & 10 & 2.1 \\
\hline Time spent on & Very good & 29 & 6.2 \\
\hline leisure activities & Good & 224 & 34.6 \\
\hline
\end{tabular}




\begin{tabular}{cccc}
\hline & Neither good nor bad & 56 & 12.0 \\
& Fair & 114 & 24.4 \\
& Poor & 25 & 3.9 \\
& Unknown & 20 & 4.3 \\
\hline \multirow{4}{*}{ Work } & Very good & 22 & 4.7 \\
& Good & 107 & 22.9 \\
relationships & Neither good nor bad & 47 & 10.0 \\
& Fair & 19 & 4.1 \\
& Poor & 1 & 0.2 \\
& Unknown & 272 & 58.1 \\
\hline
\end{tabular}

507 
508 Table 2. Correlation analysis of personal factors and CAOD total score in study 1, 2, and 3

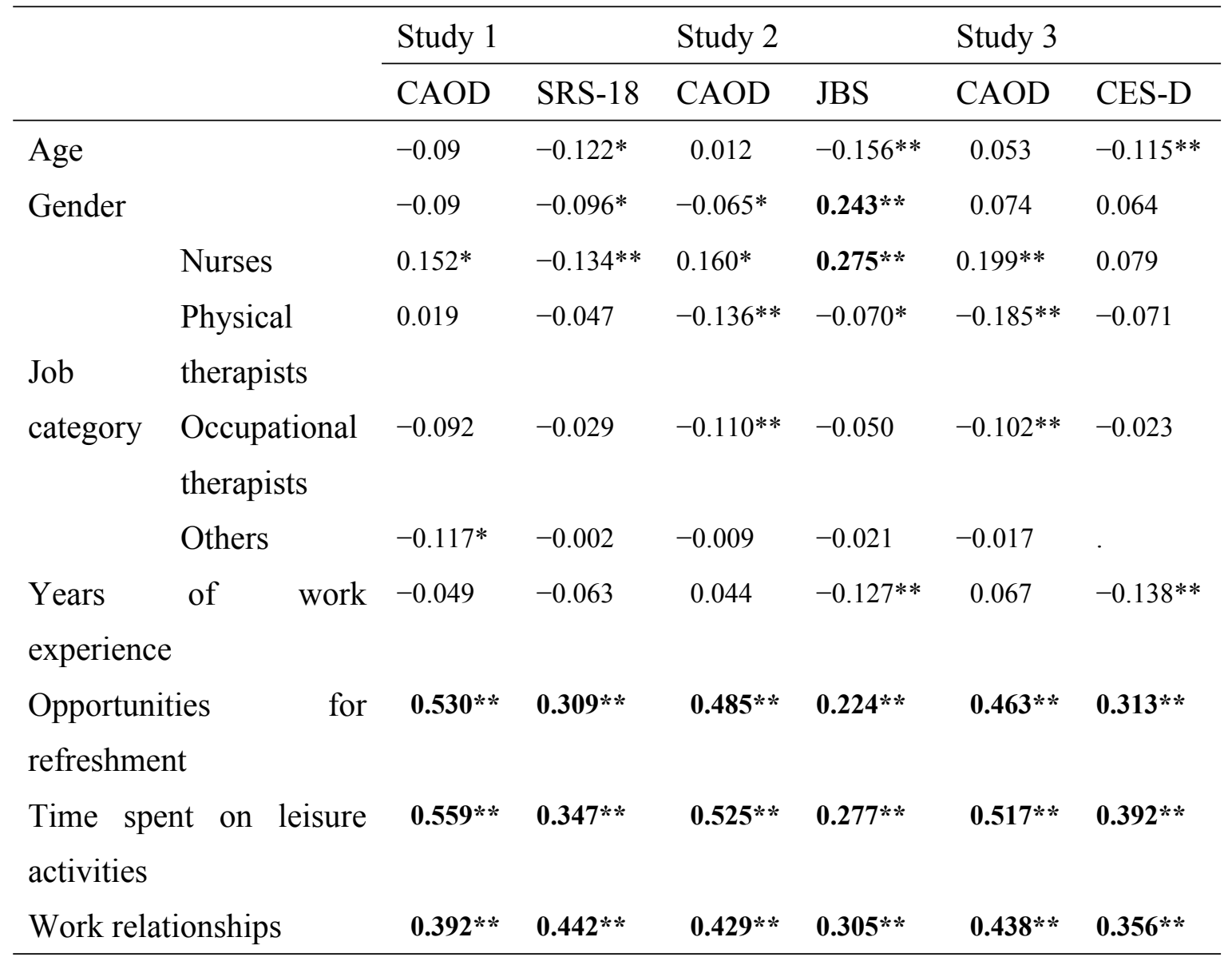

509 Note. $*=$ Significant at $5 \%$ level; $* *=$ Significant at $1 \%$ level

510 Note. Bold indicates correlation coefficient $>0.2$. 
511 Table 3. Correlation analysis between CAOD, SRS-18, JBS and CES-D.

\begin{tabular}{llllll}
\hline & & Imbalance & Deprivation & Alienation & Marginalization \\
\hline $\mathrm{S}$ & Depression & $0.342 * *$ & $0.415^{* *}$ & $0.438^{* *}$ & $0.529 * *$ \\
$\mathrm{t}$. & $\begin{array}{l}\text { and anxiety } \\
1\end{array}$ & & & & \\
& $\begin{array}{l}\text { Displeasure } \\
\text { and anger }\end{array}$ & $0.302 * *$ & $0.321 * *$ & $0.357 * *$ & $0.490 * *$ \\
& & & & \\
& Lassitude & $0.352 * *$ & $0.476^{* *}$ & $0.503 * *$ & $0.534 * *$ \\
Total SRS- & $0.382 * *$ & $0.462 * *$ & $0.492 * *$ & $0.583 * *$ \\
18 & & & & \\
\end{tabular}

\begin{tabular}{|c|c|c|c|c|c|c|}
\hline & & Imbalance & Deprivation & Alienation & Marginaliza & \\
\hline & & & & & $\begin{array}{l}\text {-tion (non- } \\
\text { shared) }\end{array}$ & $\begin{array}{l}\text {-tion } \\
\text { (shared) }\end{array}$ \\
\hline $\mathrm{S}$ & $\begin{array}{l}\text { Emotional } \\
\text { exhaustion }\end{array}$ & $0.530 * *$ & $0.417 * *$ & $0.482 * *$ & $0.480 * *$ & $0.222 * *$ \\
\hline 2 & $\begin{array}{l}\text { Depersonali } \\
\text { zation }\end{array}$ & $0.343 * *$ & $0.378 * *$ & $0.505 * *$ & $0.524 * *$ & $0.313^{* *}$ \\
\hline & $\begin{array}{l}\text { Diminished } \\
\text { personal } \\
\text { accomplish } \\
\text { ment }\end{array}$ & -0.02 & 0.014 & $0.174 * *$ & 0.021 & -0.029 \\
\hline & Total JBS & $0.306^{* *}$ & $0.288 * *$ & $0.464 * *$ & $0.376^{* *}$ & $0.168 * *$ \\
\hline S & $\begin{array}{l}\text { Depressed } \\
\text { affect }\end{array}$ & $0.400 * *$ & $0.392 * *$ & $0.476 * *$ & $0.408 * *$ & $0.251 * *$ \\
\hline 3 & $\begin{array}{l}\text { Somatic } \\
\text { symptoms }\end{array}$ & $0.438 * *$ & $0.406 * *$ & $0.481 * *$ & $0.409 * *$ & $0.272 * *$ \\
\hline & $\begin{array}{l}\text { Interpersona } \\
1 \text { difficulties }\end{array}$ & $0.178 * *$ & $0.217^{* *}$ & $0.264 * *$ & $0.369 * *$ & $0.291 * *$ \\
\hline & $\begin{array}{l}\text { Negative } \\
\text { affect }\end{array}$ & $0.177 * *$ & $0.292 * *$ & $0.380 * *$ & $0.302 * *$ & $0.191 * *$ \\
\hline & $\begin{array}{l}\text { Total CES- } \\
\text { D }\end{array}$ & $0.426 * *$ & $0.461 * *$ & $0.581 * *$ & $0.503 * *$ & $0.330 * *$ \\
\hline
\end{tabular}


513 Note. St. $=$ Study, Imbalance $=$ Occupational imbalance, Deprivation $=$ Occupational deprivation, 514 Alienation = Occupational alienation, Marginalization = Occupational marginalization, 515 Marginalization (non-shared) = Non-shared environment marginalization, Marginalization $516($ shared $)=$ Shared environment marginalization. Study 1 is separated 4 factor of CAOD, Study 2 517 and 3 are separated 5 factor of CAOD.

518 
519 Table 4. Structural relationships of CAOD and SRS-18 (study 1)

Estimate S.E. Est./S.E. Two- 95\% CI

TailedP-

Value

\section{Model fit information}

RMSEA

$0.061[90 \% \mathrm{CI}=0.057 ; 0.064]$

CFI

0.947

TLI

0.943

\section{Standardized model results}

Stress On

Occupational

dysfunction

$\begin{array}{lllll}0.748 & 0.096 & 7.771 & 0.000 & 0.500 ; 0.995\end{array}$

Covariates

$-0.062$

$0.107 \quad-0.574$

0.566

$-0.338 ; 0.215$

Occupational On

dysfunction

Covariates

0.826

0.026

31.284

0.000

$0.758 ; 0.894$

\section{Occupational by}

dysfunction

Occupational

imbalance

$\begin{array}{lllll}0.677 & 0.028 & 23.861 & 0.000 & 0.604 ; 0.750\end{array}$

Occupational

deprivation

$\begin{array}{lllll}0.893 & 0.017 & 53.737 & 0.000 & 0.850 ; 0.936\end{array}$

Occupational

alienation

0.840

0.021

39.462

0.000

$0.785 ; 0.894$

Occupational

Marginalization

0.880

0.017

52.298

0.000

$0.837 ; 0.923$

Stress by

response

Depression and anxiety
0.971
0.014
70.326
0.000
$0.935 ; 1.006$

Displeasure and anger

$\begin{array}{lllll}0.787 & 0.024 & 32.723 & 0.000 & 0.725 ; 0.849\end{array}$




\begin{tabular}{lccccc}
\multicolumn{1}{c}{ Lassitude } & 0.915 & 0.017 & 52.651 & 0.000 & $0.870 ; 0.960$ \\
\hline $\begin{array}{l}\text { Covariates Ind } \\
\text { Stress response }\end{array}$ & 0.617 & 0.086 & 7.195 & 0.000 & $0.396 ; 0.838$ \\
\hline $\begin{array}{l}\text { R Square } \\
\text { Stress response }\end{array}$ & 0.487 & 0.040 & 12.112 & 0.000 & - \\
\hline
\end{tabular}

520 Note. S.E. = Standard error, Est. / S.E. = Estimator / Standard error, CI = Confidence interval, 521 On $=$ Structural association, $\mathrm{By}=$ Constract, Ind $=$ Indirect, $\mathrm{R}$ Square $=\mathrm{R}$ coefficient of 522 determination 
523 Table 5. Sample characteristics of CAOD and JBS (study 2)

\begin{tabular}{|c|c|c|c|}
\hline & & \multicolumn{2}{|c|}{$\mathbf{M} \pm \mathbf{S D}$} \\
\hline & Total & \multicolumn{2}{|c|}{$34.5 \pm 10.2$} \\
\hline & Doctors & \multicolumn{2}{|c|}{$48.6 \pm 10.2$} \\
\hline$A$ & Nurses & \multicolumn{2}{|c|}{$36.1 \pm 10.5$} \\
\hline Age & Physical therapists & \multicolumn{2}{|c|}{$30.6 \pm 7.3$} \\
\hline & Occupational therapists & \multicolumn{2}{|c|}{$29.6 \pm 6.6$} \\
\hline & Another & \multicolumn{2}{|c|}{$37.2 \pm 11.1$} \\
\hline & Total & \multicolumn{2}{|c|}{$10.5 \pm 9.3$} \\
\hline & Doctors & \multicolumn{2}{|c|}{$23.3 \pm 10.0$} \\
\hline Years of work & Nurses & \multicolumn{2}{|c|}{$12.5 \pm 9.7$} \\
\hline experience & Physical therapists & \multicolumn{2}{|c|}{$7.0 \pm 6.4$} \\
\hline & Occupational therapists & \multicolumn{2}{|c|}{$6.4 \pm 5.7$} \\
\hline & Another & \multicolumn{2}{|c|}{$11.6 \pm 10.5$} \\
\hline & & Total N & $\%$ \\
\hline \multirow{3}{*}{ Gender } & Male & 476 & 41.6 \\
\hline & Female & 650 & 56.9 \\
\hline & Others & 16 & 1.4 \\
\hline \multirow{5}{*}{ Job category } & Doctor & 21 & 1.8 \\
\hline & $\begin{array}{l}\text { Nurse, Health nurse, } \\
\text { Midwife }\end{array}$ & 484 & 42.3 \\
\hline & Physical therapist & 205 & 17.9 \\
\hline & Occupational therapist & 180 & 15.7 \\
\hline & Other healthcare workers & 252 & 22.0 \\
\hline \multirow{6}{*}{$\begin{array}{l}\text { Opportunities } \\
\text { for refreshment }\end{array}$} & Very good & 111 & 9.7 \\
\hline & Good & 629 & 55.0 \\
\hline & Neither good nor bad & 143 & 12.5 \\
\hline & Fair & 112 & 9.8 \\
\hline & Poor & 106 & 9.2 \\
\hline & Unknown & 41 & 3.5 \\
\hline Time spent on & Very good & 82 & 7.1 \\
\hline leisure activities & Good & 509 & 44.5 \\
\hline
\end{tabular}




\begin{tabular}{cccc}
\hline & Neither good nor bad & 33 & 2.8 \\
& Fair & 237 & 20.7 \\
& Poor & 68 & 5.9 \\
& Unknown & 213 & 18.6 \\
\hline \multirow{4}{*}{ Work } & Very good & 107 & 9.3 \\
& Good & 463 & 40.5 \\
relationships & Neither good nor bad & 209 & 18.3 \\
& Fair & 48 & 4.2 \\
& Poor & 14 & 1.2 \\
& Unknown & 301 & 26.3 \\
\hline
\end{tabular}

524 
525 Table 6. Structural relationships CAOD and JBS (study 2)

Estimate S.E. Est./S.E. Two- $\quad$ T5\% CI

TailedP-

Value

\section{Model fit information}

RMSEA

$0.076[90 \% \mathrm{CI}=0.073 ; 0.078]$

CFI

0.919

TLI

0.913

\section{Standardized model results}

Burnout On

Occupational

dysfunction

$\begin{array}{lllll}0.876 & 0.060 & 14.714 & 0.000 & 0.723 ; 1.029\end{array}$

Covariates

$\begin{array}{lll}-0.173 & 0.068 & -2.538\end{array}$

0.011

$-0.349 ; 0.003$

Occupational On

dysfunction

\begin{tabular}{llllll} 
Covariates & 0.796 & 0.018 & 45.214 & 0.000 & $0.750 ; 0.841$ \\
\hline $\begin{array}{l}\text { Occupational by } \\
\text { dysfunction } \\
\begin{array}{l}\text { Occupational } \\
\text { imbalance }\end{array}\end{array}$ & 0.714 & 0.017 & 41.649 & 0.000 & $0.670 ; 0.758$ \\
$\begin{array}{l}\text { Occupational } \\
\text { deprivation }\end{array}$ & 0.884 & 0.010 & 86.646 & 0.000 & $0.857 ; 0.910$ \\
$\begin{array}{l}\text { Occupational } \\
\text { alienation }\end{array}$ & 0.855 & 0.012 & 70.107 & 0.000 & $0.824 ; 0.886$ \\
$\begin{array}{l}\text { Occupational } \\
\text { Marginalization } \\
\text { (non shared) }\end{array}$ & 0.888 & 0.011 & 84.104 & 0.000 & $0.861 ; 0.916$ \\
$\begin{array}{l}\text { Occupational } \\
\text { marginalization } \\
\text { (shared) }\end{array}$ & 0.615 & 0.024 & 25.447 & 0.000 & $0.552 ; 0.677$ \\
\hline
\end{tabular}

\section{Burnout by}

syndrome 
Emotional

exhaustion

$$
\begin{array}{lllll}
0.971 & 0.014 & 67.697 & 0.000 & 0.934 ; 1.008
\end{array}
$$

Depersonalizatio

$\mathrm{n}$

$\begin{array}{lllll}0.871 & 0.016 & 55.916 & 0.000 & 0.831 ; 0.911\end{array}$

Diminished

$\begin{array}{lllllll}\text { personal acco- } & 0.178 & 0.032 & 5.642 & 0.000 & 0.097 ; & 0.260\end{array}$ mplishment

Covariates Ind

Burnout

syndrome

$\begin{array}{lllll}0.697 & 0.055 & 12.725 & 0.000 & 0.556 ; 0.838\end{array}$

R Square

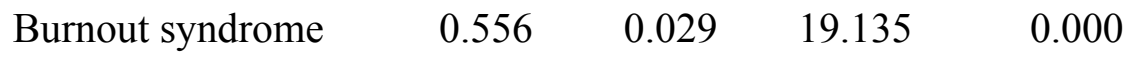

526 Note. S.E. = Standard error, Est. / S.E. = Estimator / Standard error, CI = Confidence interval,

527 On $=$ Structural association, By $=$ Constract, Ind $=$ Indirect, $\mathrm{R}$ Square $=\mathrm{R}$ coefficient of 528 determination 
529 Table 7. Sample characteristics of CAOD and CES-D (study 3)

\begin{tabular}{|c|c|c|c|}
\hline & & \multicolumn{2}{|c|}{$\mathbf{M} \pm \mathbf{S D}$} \\
\hline \multirow{4}{*}{ Age } & Total & \multicolumn{2}{|c|}{$33.6 \pm 10.2$} \\
\hline & Nurses & \multicolumn{2}{|c|}{$37.4 \pm 11.2$} \\
\hline & Physical therapists & \multicolumn{2}{|c|}{$29.3 \pm 6.4$} \\
\hline & Occupational therapists & \multicolumn{2}{|c|}{$27.6 \pm 4.1$} \\
\hline \multirow{5}{*}{$\begin{array}{c}\text { Years of work } \\
\text { experience }\end{array}$} & Total & \multicolumn{2}{|c|}{$9.67 \pm 9.2$} \\
\hline & Nurses & \multicolumn{2}{|c|}{$12.8 \pm 10.3$} \\
\hline & Physical therapists & \multicolumn{2}{|c|}{$5.64 \pm 5.3$} \\
\hline & Occupational therapists & \multicolumn{2}{|c|}{$4.84 \pm 3.5$} \\
\hline & & Total N & $\%$ \\
\hline \multirow{3}{*}{ Gender } & Male & 159 & 23.5 \\
\hline & Female & 509 & 75.4 \\
\hline & Unknown & 7 & 1.0 \\
\hline \multirow{6}{*}{ Job category } & Nurse & 326 & 48.2 \\
\hline & Health nurse, Midwife & 12 & 1.7 \\
\hline & Assistant nurse & 63 & 9.3 \\
\hline & Physical therapist & 155 & 22.9 \\
\hline & Occupational therapist & 123 & 18.2 \\
\hline & Unknown & 8 & 1.1 \\
\hline \multirow{6}{*}{$\begin{array}{l}\text { Opportunities } \\
\text { for refreshment }\end{array}$} & Very good & 71 & 10.5 \\
\hline & Good & 364 & 54 \\
\hline & Neither good nor bad & 91 & 13.5 \\
\hline & Fair & 56 & 8.3 \\
\hline & Poor & 62 & 9.1 \\
\hline & Unknown & 30 & 4.4 \\
\hline \multirow{6}{*}{$\begin{array}{l}\text { Time spent on } \\
\text { leisure activities }\end{array}$} & Very good & 53 & 7.8 \\
\hline & Good & 285 & 42.2 \\
\hline & Neither good nor bad & 141 & 20.9 \\
\hline & Fair & 123 & 18.2 \\
\hline & Poor & 43 & 6.3 \\
\hline & Unknown & 29 & 4.3 \\
\hline
\end{tabular}




\begin{tabular}{clcc}
\hline & Very good & 85 & 12.6 \\
& Good & 356 & 52.8 \\
Work & Neither good nor bad & 162 & 24 \\
relationships & Fair & 29 & 4.3 \\
& Poor & 13 & 1.9 \\
& Unknown & 29 & 4.3 \\
\hline
\end{tabular}

530 
531 Table 8. Structural relationships CAOD and CES-D (study 3)

Estimate S.E. Est./S.E. Two- $\quad$ 95\% CI

TailedP-

Value

\section{Model fit information}

RMSEA

$0.060[90 \% \mathrm{CI}=0.057 ; 0.063]$

CFI

0.922

TLI

0.917

\section{Standardized model results}

Depression On

Occupational

dysfunction

$\begin{array}{lllll}0.695 & 0.067 & 10.301 & 0.000 & 0.521 ; 0.869\end{array}$

Covariates

$\begin{array}{lll}0.063 & 0.076 & 0.829\end{array}$

0.407

$-0.133 ; 0.259$

Occupational On

dysfunction

\begin{tabular}{|c|c|c|c|c|c|}
\hline Covariates & 0.783 & 0.023 & 33.791 & 0.000 & $0.723 ; 0.842$ \\
\hline \multicolumn{6}{|l|}{$\begin{array}{l}\text { Occupational } \\
\text { dysfunction }\end{array}$} \\
\hline $\begin{array}{l}\text { Occupational } \\
\text { imbalance }\end{array}$ & 0.688 & 0.025 & 27.477 & 0.000 & $0.624 ; 0.753$ \\
\hline $\begin{array}{l}\text { Occupational } \\
\text { deprivation }\end{array}$ & 0.898 & 0.015 & 57.989 & 0.000 & $0.858 ; 0.938$ \\
\hline $\begin{array}{l}\text { Occupational } \\
\text { alienation }\end{array}$ & 0.874 & 0.015 & 56.918 & 0.000 & $0.835 ; 0.914$ \\
\hline \multicolumn{6}{|l|}{ Occupational } \\
\hline $\begin{array}{l}\text { Marginalization } \\
\text { (non shared) }\end{array}$ & 0.879 & 0.014 & 61.800 & 0.000 & $0.843 ; 0.916$ \\
\hline $\begin{array}{l}\text { Occupational } \\
\text { marginalization } \\
\text { (shared) }\end{array}$ & 0.632 & 0.032 & 19.721 & 0.000 & $0.549 ; 0.714$ \\
\hline \multicolumn{6}{|l|}{ Depression by } \\
\hline Depressed affect & 0.960 & 0.015 & 65.960 & 0.000 & $0.922 ; 0.997$ \\
\hline
\end{tabular}




\begin{tabular}{lccccc}
$\begin{array}{l}\text { Somatic } \\
\text { symptoms }\end{array}$ & 0.915 & 0.017 & 54.215 & 0.000 & $0.872 ; 0.959$ \\
$\begin{array}{l}\text { Interpersonal } \\
\text { difficulties }\end{array}$ & 0.785 & 0.032 & 24.395 & 0.000 & $0.702 ; 0.868$ \\
$\quad \begin{array}{l}\text { Negative affect } \\
\text { ind }\end{array}$ & 0.543 & 0.041 & 13.098 & 0.000 & $0.436 ; 0.649$ \\
\hline $\begin{array}{l}\text { Covariates } \\
\text { Depression }\end{array}$ & 0.544 & 0.057 & 9.578 & 0.000 & $0.398 ; 0.690$ \\
\hline $\begin{array}{l}\text { R Square } \\
\text { Depression }\end{array}$ & 0.556 & 0.031 & 17.714 & 0.000 & - \\
\hline
\end{tabular}

532 Note. S.E. = Standard error, Est. / S.E. = Estimator / Standard error, CI = Confidence interval, 533 On $=$ Structural association, $B y=$ Constract, Ind $=$ Indirect, $\mathrm{R}$ Square $=\mathrm{R}$ coefficient of 534 determination 


\section{References}

536 [1] Jackson Jeanne, Carlson Mike, Mandel Deborah, Zemke Ruth, Clark Florence (1998)

537 Occupation in lifestyle redesign: the Well Elderly Study Occupational Therapy Program.

$538 \quad$ Am J Occup Ther 52: 326-336.

539 [2] Mandel Deborah R, Association AOT (1999) Lifestyle redesign: Implementing the well

541 [3] Horowitz Beverly P, Chang Pei-Fen J (2004) Promoting well-being and engagement in life through occupational therapy lifestyle redesign: A pilot study within adult day programs. Topics in Geriatric Rehabilitation 20: 46-58.

[4] Scaffa Marjorie E, Reitz Maggie S (2013) Occupational Therapy Community-Based Practice Settings.

[5] Teraoka Mutsumi, Kyougoku Makoto (2014) Development of occupation-based practice 2.0 that integrates occupation based-practice and dissolution approach for belief conflict. Japanese occupational therapy research 33: 249-258.

[6] Teraoka Mutsumi, Kyougoku Makoto (2015) Development of the Final Version of the Classification and Assessment of Occupational Dysfunction Scale. PLoS ONE 10(8): e0134695. doi:10.1371/journal.pone.0134695.

554

[7] Townsend Elizabeth, Wilcock Ann A (2004) Occupational justice and client-centred practice: a dialogue in progress. Canadian Journal of Occupational Therapy 71: 75-87.

[8] Gail Whiteford (2000) Occupational deprivation: Global challenge in the new millennium. The British Journal of Occupational Therapy 63: 200-204.

[9] Wendy Bryant, Christine Craik, McKay Elizabeth A (2004) Living in a glasshouse: exploring occupational alienation. Canadian Journal of Occupational Therapy 71: 282-289.

[10] Dana Anaby, Tal Jarus, Backman Catherine L, Zumbo Bruno D (2010) The role of occupational characteristics and occupational imbalance in explaining well-being. Applied Research in Quality of Life 5: 81-104.

[11] Kyougoku Makoto (2010) Unstructured assessment for occupational therapy, 4 condition method. Tokyo: Seisin-shoboo.

[12] Ishii Yoshikazu, Kyougoku, Makoto, Nagao Sinichiro. (2010) Occupational therapy of mental health; Ishii Y, Kyougoku, M., Nagao S., editor. Tokyo: Chuohoki. workers: using occupational self assessment version2 (OSA2). Sogo Rehabilitation 38: 373- 
567

568

569

570

571

572

573

574

575

576

577

578

579

580

581

582

583

584

585

586

587

588

589

590

591

592

593

594

595

596

597

598

379.

[14] Miyake Yuki, Teraoka Mutsumi, Ogino Keiki, Kyougoku Makoto (2014) Survey of the classification of occupational dysfunction among japanese rehabilitation therapists and the association of occupational dysfunction with job strain. Journal of Preventive Medicine 9: 93-100.

[15] Irvine Donald (1997) The performance of doctors. I: Professionalism and self regulation in a changing world. BMJ: British Medical Journal 314: 1540.

[16] Van Praag HM (2004) Can stress cause depression? Progress in NeuroPsychopharmacology and Biological Psychiatry 28: 891-907.

[17] NIOSH (1999) Stress at Work.

[18] Cooper Cary L, Dewe Philip J, O'Driscoll Michael P (2001) Organizational stress: A review and critique of theory, research, and applications: Sage.

[19] Wright Jennifer (2007) Stress in the workplace: A coaching approach. Work: A Journal of Prevention, Assessment and Rehabilitation 28: 279-284.

[20] Peterson Ulla, Bergström Gunnar, Demerouti Evangellia, Gustavsson Petter, Åsberg Marie, Nygren Åke. (2011) Burnout levels and self-rated health prospectively predict future longterm sickness absence: a study among female health professionals. Journal of Occupational and Environmental Medicine 53: 788-793.

[21] Moghaddasi Jaefer, Mehralian Hossein, Aslani Yousef, Masoodi Reza, Amiri Masoud (2013) Burnout among nurses working in medical and educational centers in Shahrekord, Iran. Iran J Nurs Midwifery Res 18: 294-297.

[22] Drury Vicki, Craigie Mark, Francis Karen, Aoun Samar, Hegney Desley G (2014) Compassion satisfaction, compassion fatigue, anxiety, depression and stress in registered nurses in Australia: phase 2 results. Journal of Nursing Management 22: 519-531.

[23] Tamakoshi Akiko, Ohno Yoshiyuki, Yamada Takuji, Aoki Kunio, Hamajima Nobuyuki, Wada Masaya, Kawamura Takashi, Wakai Kenji, Lin Ying Song. (2000) Depressive mood and suicide among middle-aged workers: findings from a prospective cohort study in Nagoya, Japan. Journal of epidemiology/Japan Epidemiological Association 10: 173-178.

[24] Takeuchi Takeaki, Nakao Mutsuhiro (2013) The relationship between suicidal ideation and symptoms of depression in Japanese workers: a cross-sectional study. BMJ open 3: e003643.

[25] Honda Ayumi, Date Yutaka, Abe Yasuyo, Aoyagi Kiyoshi, Honda Sumihisa (2014) Workrelated Stress, Caregiver Role, and Depressive Symptoms among Japanese Workers. Safety 
599

600

601

602

603

604

605

606

607

608

609

610

611

612

613

614

615

616

617

618

619

620

621

622

623

624

625

626

627

628

629

630

and Health at Work 5: 7-12.

[26] Kato Rika, Haruyama Yasuo, Endo Motoki, Tsutsumi Akizumi, Muto Tetsuichiro (2014) Heavy overtime work and depressive disorder among male workers. Occupational Medicine: kqu120.

[27] Denton Margaret, Zeytinoglu Isik Urla, Davies Sharon, Lian Jason (2002) Job stress and job dissatisfaction of home care workers in the context of health care restructuring. International Journal of Health Services 32: 327-357.

[28] Schaefer Jeanne A, Moos Rudolf H (1993) Relationship, task and system stressors in the health care workplace. Journal of Community \& Applied Social Psychology 3: 285-298.

[29] Seki Yukiko, Yamazaki Yoshihiko (2006) Effects of working conditions on intravenous medication errors in a Japanese hospital. Journal of nursing management 14: 128-139.

[30] Matsudaira Ko, Shimazu Akihito, Fujii Tomoko, Kubota Kazumi, Sawada Takayuki, Kikuchi Norimasa, Takahashi Masaya. (2013) Workaholism as a Risk Factor for Depressive Mood, Disabling Back Pain, and Sickness Absence. PloS one 8: e75140.

[31] Health NIfOSa (2008) Exposure to stress: occupational hazards in hospitals. Cincinnati: National Institute for Occupational Safety and Health.

[32] Wilcock Ann A, Hocking Clare (2015) An Occupational Perspective of Health, Third Edition Edition: Slack Incorporated

[33] Ullman Jodie B, Bentler Peter M (2003) Structural equation modeling: Wiley Online Library.

[34] Muthen Linda K, Muthen Bengt O (2012) Mplus user's guide. Seventh edition. Los Angeles, CA: Muthen \& Muthen

[35] Kyougoku Makoto (2011) Dissolution approach for belief conflict in heathcare: Introduction to communication skill. Tokyo: Seishin shobo.

[36] Kazuhito Sato, Hiroaki Otsu, Hirokazu Madokoro, Sakura Kadowaki. Analysis of Psychological Stress Factors and Facial Parts Effect on Intentional Facial Expressions; 2013. pp. 7-16.

[37] Asparouhov Tihomir, Muthén Bengt (2010) Weighted least squares estimation with missing data. MplusTechnical Appendix.

[38] Kline Rex B (2011) Principles and practice of structural equation modeling: Guilford press.

[39] Timothy Brown A (2015) Confirmatory factor analysis for applied reseach $2^{\text {nd }}$ edition. New york: The guilford press. 
631 [40] Kubo Makoto (2014) The factorial and construct validity of the Japanese Burnout Scale 632 among service workers. Japanese Journal of Psychology 85: 364-372.

633 [41] Shima Satoshi, Shikano Tatsuo, Kitamura Toshinori, Asai Masahiro (1985) New self-rating $634 \quad$ scales for depression. Clinical Psychiatry 27: 717-723.

635 [42] Kyougoku Makoto, Teraoka Mutsumi, Masuda Noriko, Oomura Mariko, Abe Yasushi 636 (2015) Development of the Assessment of Belief Conflict in Relationship-14 (ABCR-14). 637 PLoS ONE 10(8): e0129349. doi:10.1371/journal.pone.0129349. 


\section{Figure 1 (on next page)}

Figure1

The hypothesized model of structural relationship 


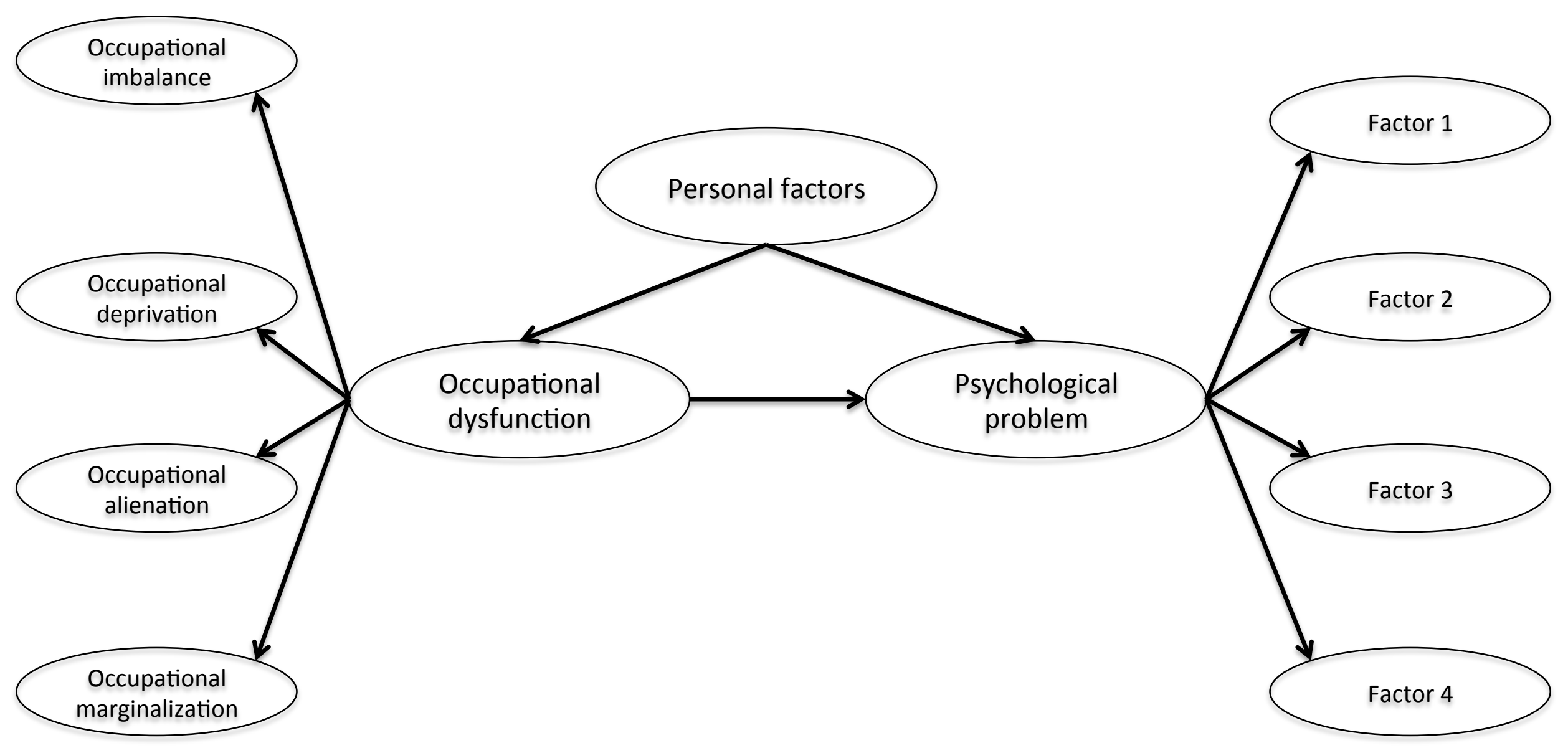




\section{Figure 2 (on next page)}

Figure2

Occupation based practice 2.0 (OBP2.0) model 


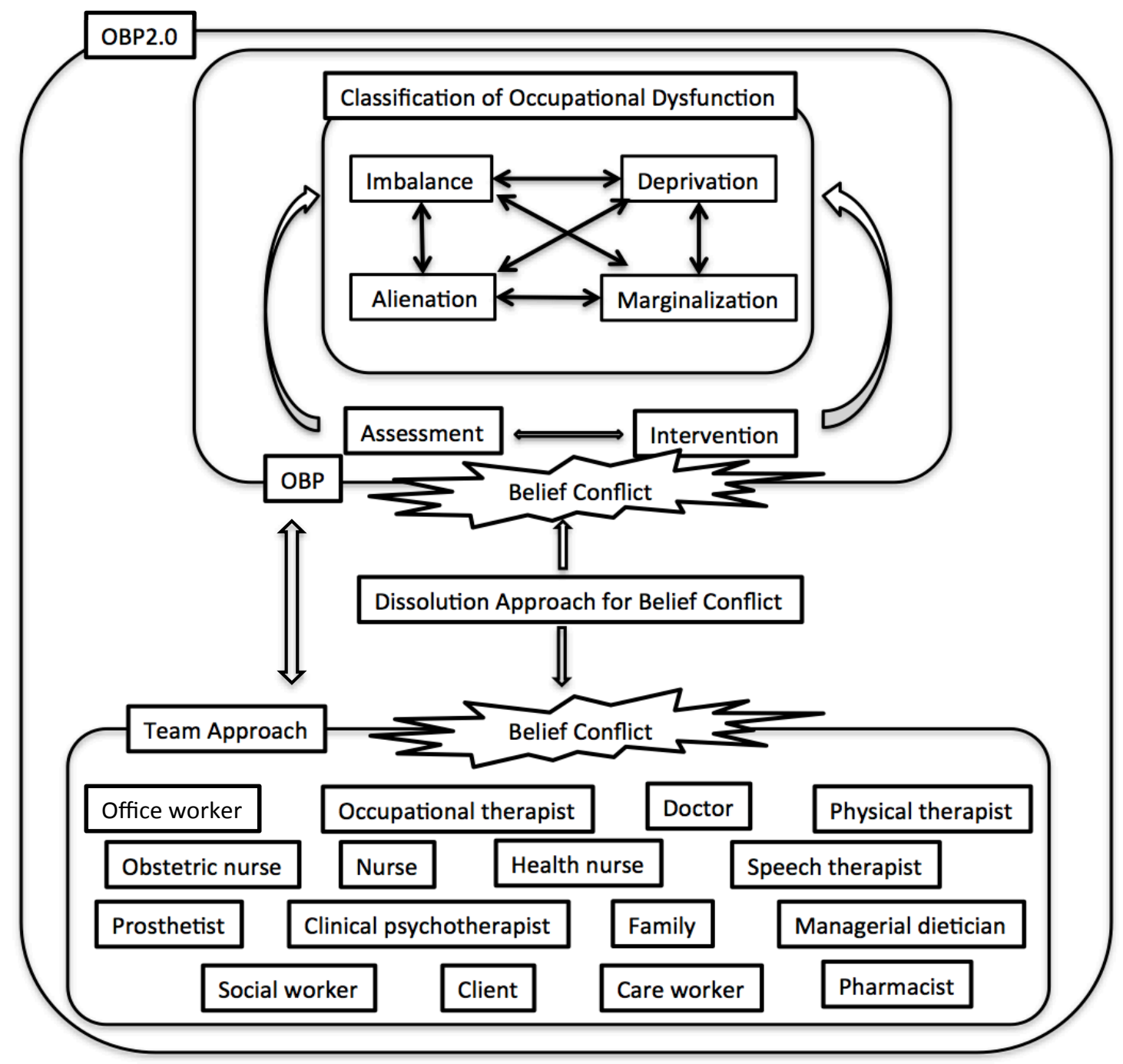




\section{Figure $\mathbf{3}$ (on next page)}

Figure3

\section{CFA of CAOD (study 1)}




\subsection{4}

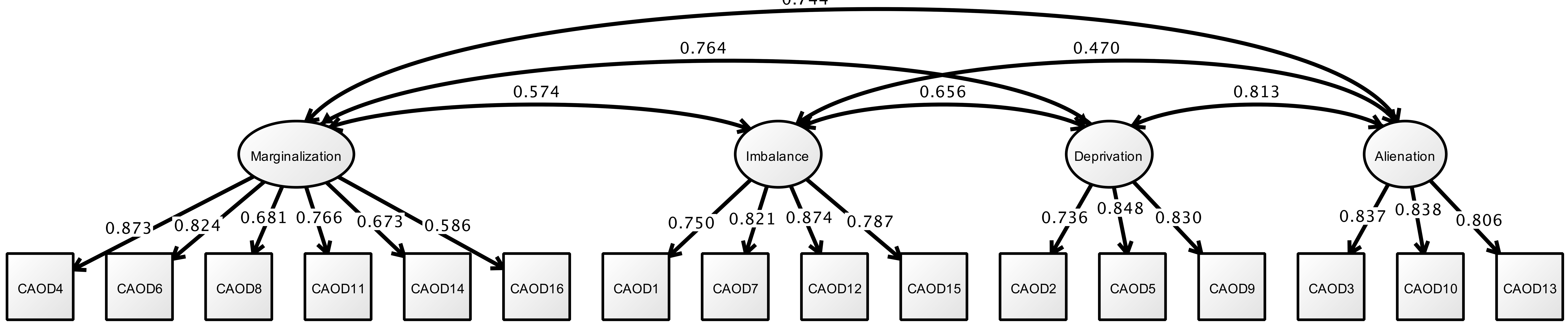


Figure 4 (on next page)

Figure4

CFA of SRS-18 (study 1) 


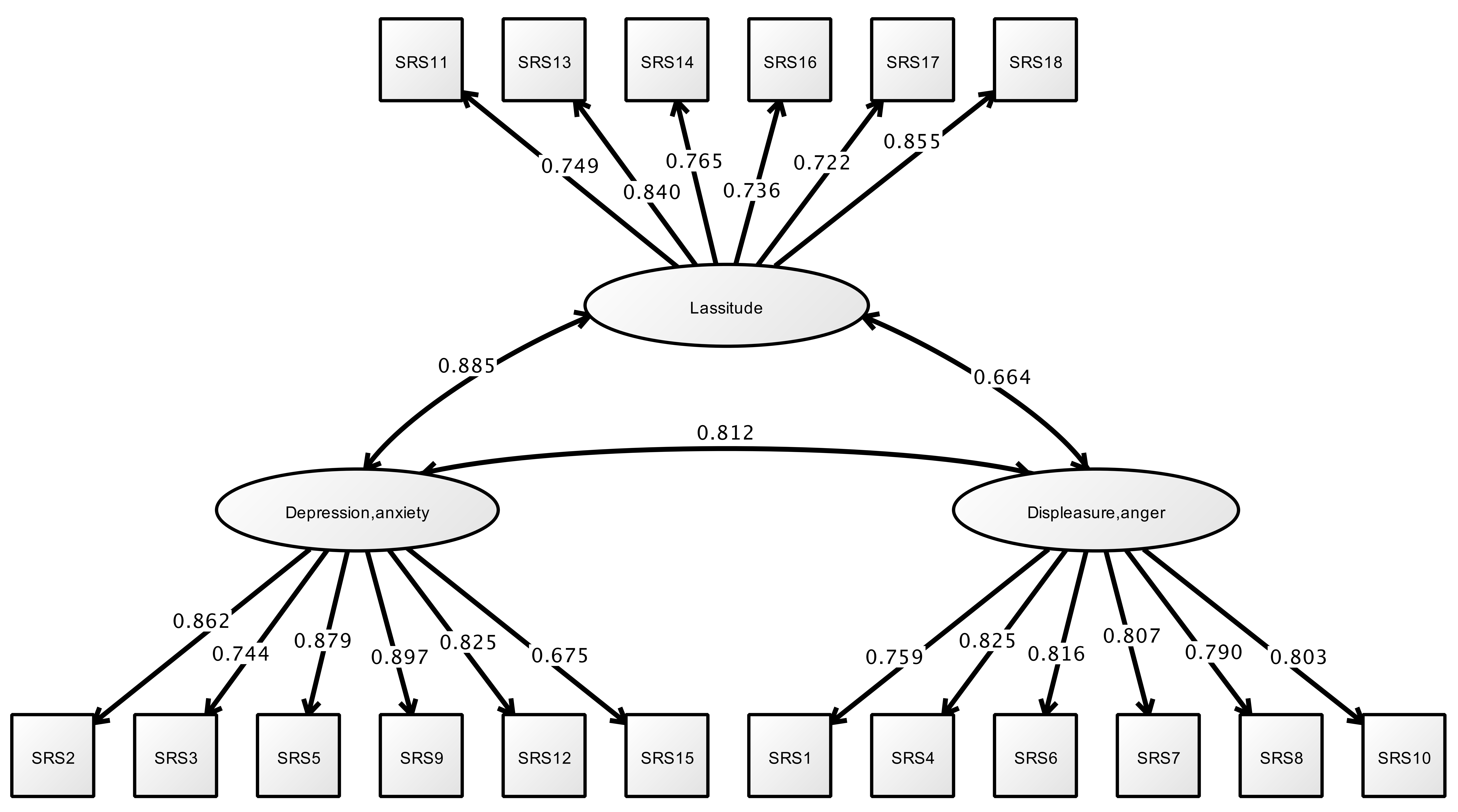




\section{Figure $\mathbf{5}$ (on next page)}

Figure5

Structural relationships of SRS-18 on CAOD (study 1) 


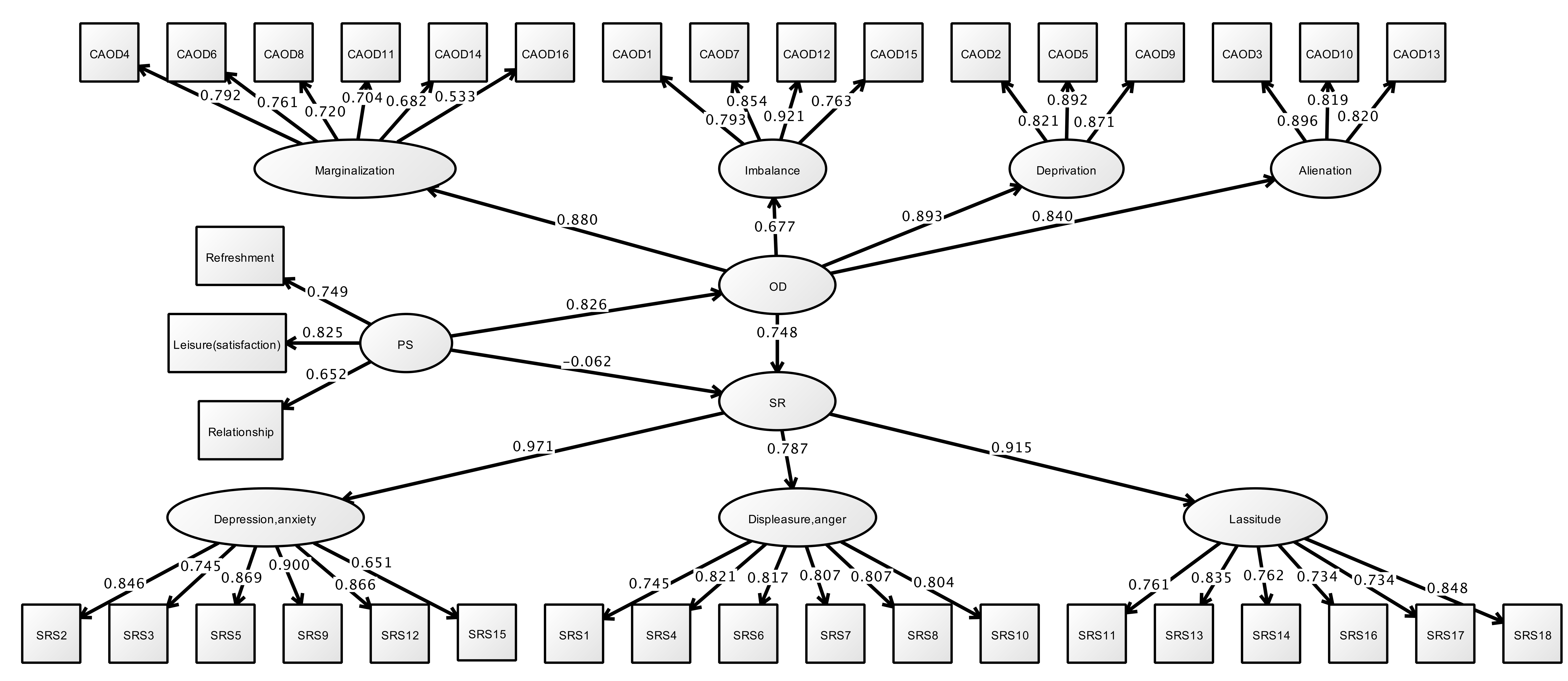




\section{Figure $\mathbf{6}$ (on next page)}

Figure6

\section{CFA of CAOD (study 2)}




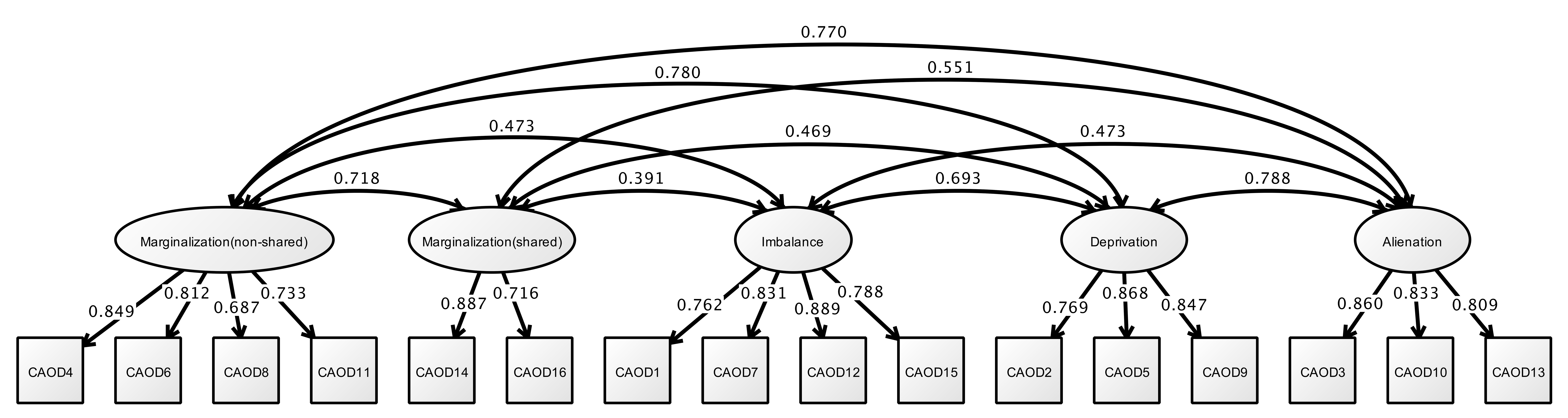


Figure 7 (on next page)

Figure7

CFA of JBS (study 2) 


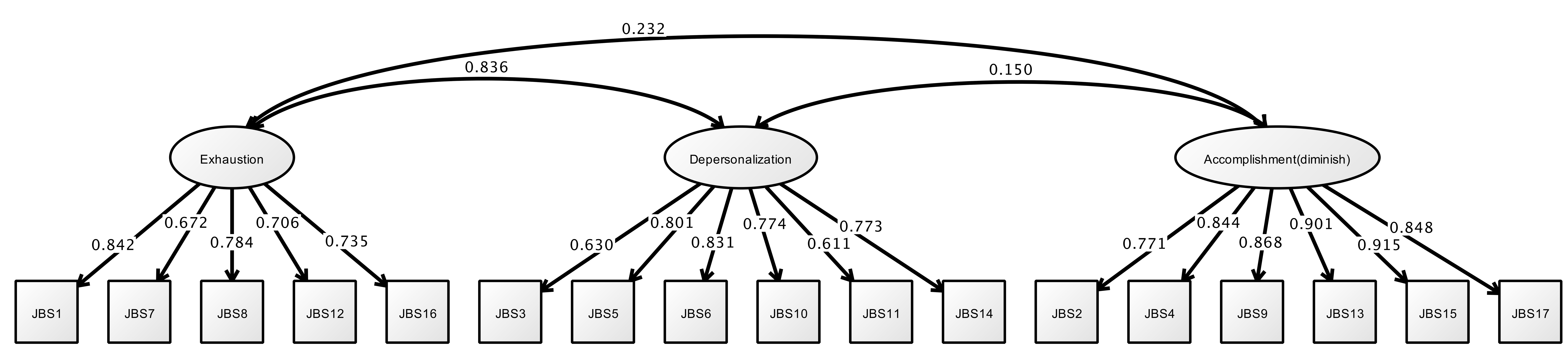




\section{Figure 8 (on next page)}

Figure8

Structural relationships of JBS on CAOD (study 2) 


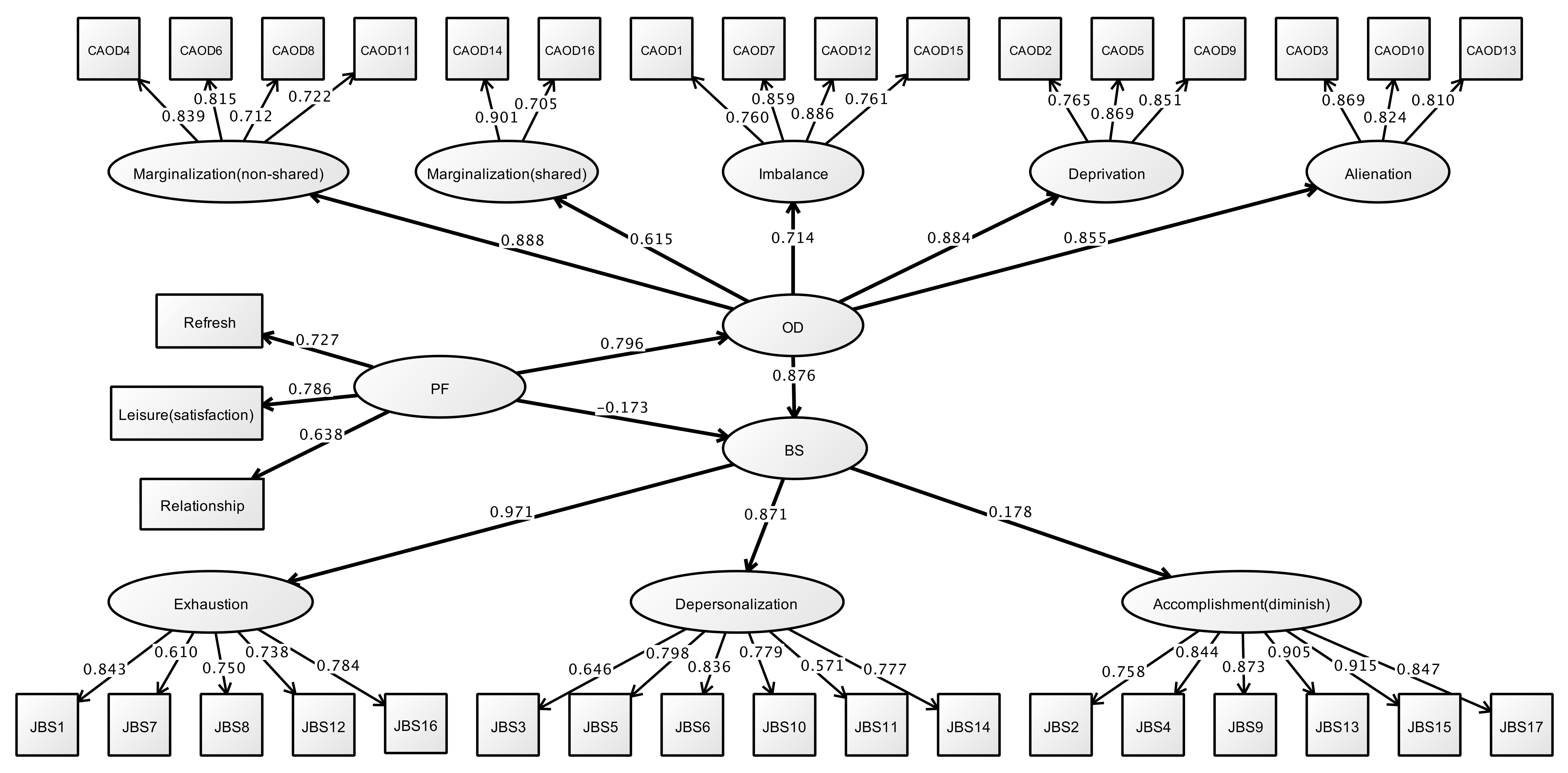




\section{Figure 9 (on next page)}

Figure9

\section{CFA of CAOD (study 3)}




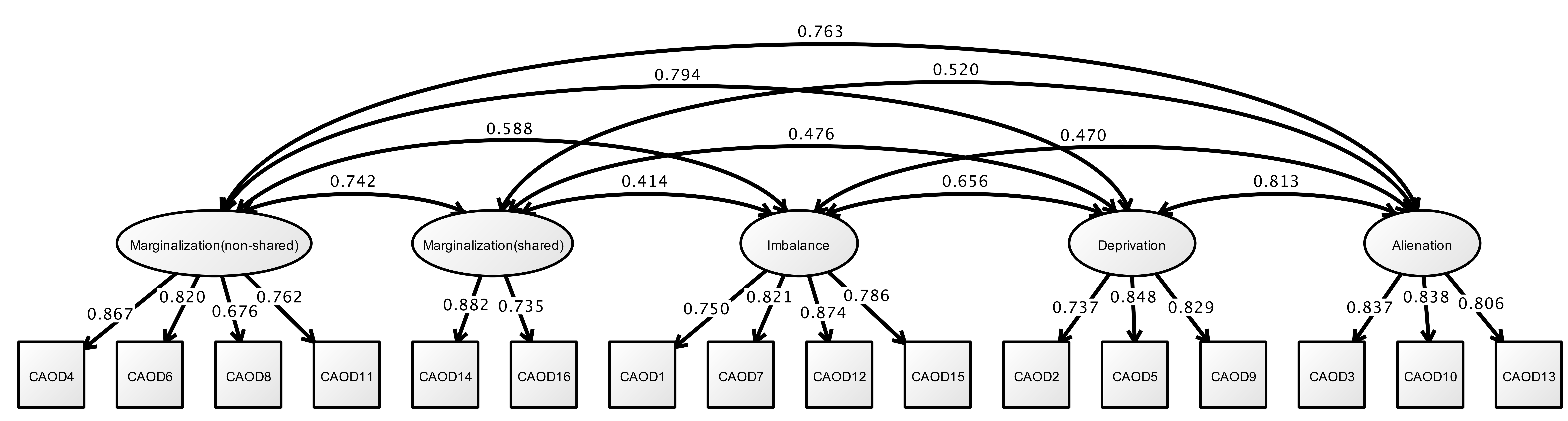


Figure $\mathbf{1 0}$ (on next page)

Figure10

CFA of CESD (study 3) 


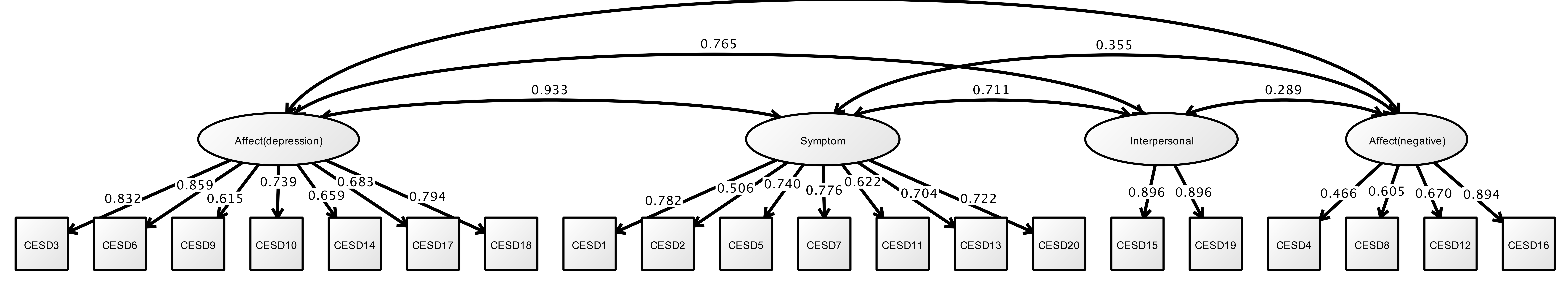


Figure 11(on next page)

Figure11

Structural relationships of CES-D on CAOD (study 3) 


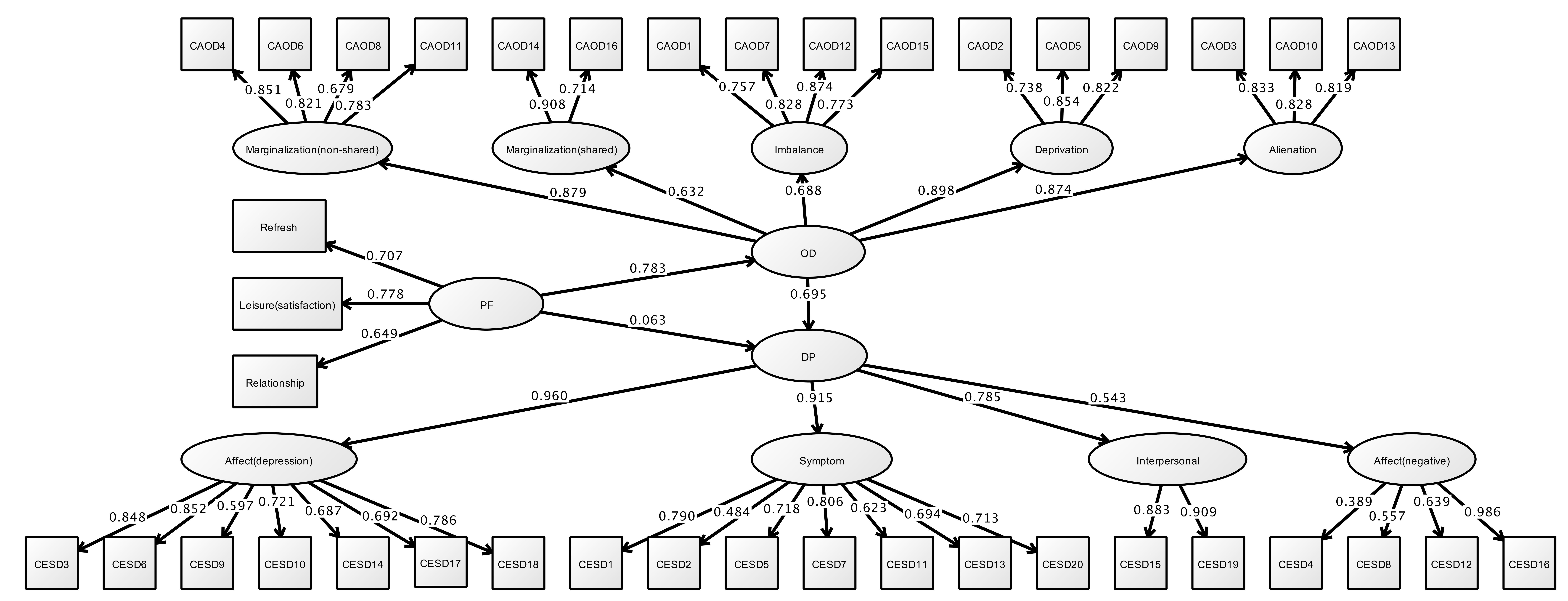




\section{Table $\mathbf{1}$ (on next page)}

Table1

Sample characteristics of CAOD and SRS-18 
1 Table 1. Sample characteristics of CAOD and SRS-18 (study 1)

\begin{tabular}{|c|c|c|c|}
\hline & & \multicolumn{2}{|c|}{$\mathbf{M} \pm \mathbf{S D}$} \\
\hline & Total & \multicolumn{2}{|c|}{$35.8 \pm 10.2$} \\
\hline & Doctors & \multicolumn{2}{|c|}{$48.6 \pm 10.2$} \\
\hline 1 & Nurses & \multicolumn{2}{|c|}{$36.1 \pm 10.8$} \\
\hline Age & Physical therapists & \multicolumn{2}{|c|}{$34.4 \pm 8.5$} \\
\hline & Occupational therapists & \multicolumn{2}{|c|}{$33.7 \pm 8.3$} \\
\hline & Others & \multicolumn{2}{|c|}{$34.9 \pm 9.3$} \\
\hline & Total & \multicolumn{2}{|c|}{$11.8 \pm 9.4$} \\
\hline & Doctors & \multicolumn{2}{|c|}{$23.3 \pm 10.0$} \\
\hline Years of work & Nurses & \multicolumn{2}{|c|}{$13.5 \pm 10.2$} \\
\hline experience & Physical therapists & \multicolumn{2}{|c|}{$10.9 \pm 7.6$} \\
\hline & Occupational therapists & \multicolumn{2}{|c|}{$9.62 \pm 7.7$} \\
\hline & Others & \multicolumn{2}{|c|}{$9.68 \pm 8.3$} \\
\hline & & Total N & $\%$ \\
\hline \multirow{3}{*}{ Gender } & Male & 141 & 30.1 \\
\hline & Female & 317 & 67.7 \\
\hline & Others & 10 & 2.1 \\
\hline \multirow{5}{*}{ Job category } & Doctor & 21 & 4.5 \\
\hline & $\begin{array}{l}\text { Nurse, Health nurse, } \\
\text { Midwife }\end{array}$ & 159 & 34.0 \\
\hline & Physical therapist & 52 & 11.1 \\
\hline & Occupational therapist & 60 & 12.8 \\
\hline & Other healthcare workers & 176 & 37.6 \\
\hline \multirow{6}{*}{$\begin{array}{l}\text { Opportunities } \\
\text { for refreshment }\end{array}$} & Very good & 41 & 8.7 \\
\hline & Good & 265 & 56.6 \\
\hline & Neither good nor bad & 52 & 11.1 \\
\hline & Fair & 56 & 11.9 \\
\hline & Poor & 44 & 9.4 \\
\hline & Unknown & 10 & 2.1 \\
\hline Time spent on & Very good & 29 & 6.2 \\
\hline leisure activities & Good & 224 & 34.6 \\
\hline
\end{tabular}




\begin{tabular}{cccc}
\hline & Neither good nor bad & 56 & 12.0 \\
& Fair & 114 & 24.4 \\
& Poor & 25 & 3.9 \\
& Unknown & 20 & 4.3 \\
\hline \multirow{2}{*}{ Work } & Very good & 22 & 4.7 \\
& Good & 107 & 22.9 \\
relationships & Neither good nor bad & 47 & 10.0 \\
& Fair & 19 & 4.1 \\
& Poor & 1 & 0.2 \\
& Unknown & 272 & 58.1 \\
\hline
\end{tabular}

2 


\section{Table 2 (on next page)}

Table 2

Correlation analysis of personal factors and CAOD 
1 Table 2. Correlation analysis of personal factors and CAOD total score in study 1, 2, and 3

\begin{tabular}{|c|c|c|c|c|c|c|c|}
\hline & \multicolumn{2}{|l|}{ Study 1} & \multicolumn{2}{|l|}{ Study 2} & \multicolumn{2}{|l|}{ Study 3} \\
\hline & & CAOD & SRS-18 & CAOD & JBS & CAOD & CES-D \\
\hline \multicolumn{2}{|l|}{ Age } & -0.09 & $-0.122 *$ & 0.012 & $-0.156^{* *}$ & 0.053 & $-0.115^{* *}$ \\
\hline \multicolumn{2}{|l|}{ Gender } & -0.09 & $-0.096^{*}$ & $-0.065^{*}$ & $0.243 * *$ & 0.074 & 0.064 \\
\hline \multirow{5}{*}{$\begin{array}{l}\text { Job } \\
\text { category }\end{array}$} & Nurses & $0.152^{*}$ & $-0.134 * *$ & $0.160^{*}$ & $0.275^{* *}$ & $0.199 * *$ & 0.079 \\
\hline & Physical & 0.019 & -0.047 & $-0.136^{* *}$ & $-0.070^{*}$ & $-0.185^{* *}$ & -0.071 \\
\hline & therapists & & & & & & \\
\hline & $\begin{array}{l}\text { Occupational } \\
\text { therapists }\end{array}$ & -0.092 & -0.029 & $-0.110 * *$ & -0.050 & $-0.102 * *$ & -0.023 \\
\hline & Others & $-0.117^{*}$ & -0.002 & -0.009 & -0.021 & -0.017 & . \\
\hline $\begin{array}{l}\text { Years } \\
\text { experien }\end{array}$ & of work & -0.049 & -0.063 & 0.044 & $-0.127^{* *}$ & 0.067 & $-0.138^{* *}$ \\
\hline \multicolumn{8}{|c|}{ refreshment } \\
\hline \multicolumn{2}{|c|}{$\begin{array}{l}\text { Time spent on leisure } \\
\text { activities }\end{array}$} & $0.559 * *$ & $0.347 * *$ & $0.525 * *$ & $0.277 * *$ & $0.517 * *$ & $0.392 * *$ \\
\hline \multicolumn{2}{|c|}{ Work relationships } & $0.392 * *$ & $0.442 * *$ & $0.429 * *$ & $0.305 * *$ & $0.438 * *$ & $0.356 * *$ \\
\hline
\end{tabular}

2 Note. $*=$ Significant at $5 \%$ level; $* *=$ Significant at $1 \%$ level

3 Note. Bold indicates correlation coefficient $>0.2$. 


\section{Table 3 (on next page)}

Table 3

Correlation analysis between CAOD, SRS-18, JBS, and CES-D 
1 Table 3. Correlation analysis between CAOD, SRS-18, JBS and CES-D.

\begin{tabular}{|c|c|c|c|c|c|}
\hline & & Imbalance & Deprivation & Alienation & Marginalization \\
\hline $\mathrm{S}$ & Depression & $0.342 * *$ & $0.415 * *$ & $0.438 * *$ & $0.529 * *$ \\
\hline t. & and anxiety & & & & \\
\hline \multirow[t]{5}{*}{1} & Displeasure & $0.302 * *$ & $0.321 * *$ & $0.357 * *$ & $0.490 * *$ \\
\hline & and anger & & & & \\
\hline & Lassitude & $0.352 * *$ & $0.476 * *$ & $0.503 * *$ & $0.534 * *$ \\
\hline & Total SRS- & $0.382 * *$ & $0.462 * *$ & $0.492 * *$ & $0.583 * *$ \\
\hline & 18 & & & & \\
\hline
\end{tabular}

\begin{tabular}{|c|c|c|c|c|c|c|}
\hline & & \multirow[t]{2}{*}{ Imbalance } & \multirow[t]{2}{*}{ Deprivation } & \multirow[t]{2}{*}{ Alienation } & & \multirow{2}{*}{$\begin{array}{l}\text { Marginaliza } \\
\text {-tion } \\
\text { (shared) }\end{array}$} \\
\hline & & & & & $\begin{array}{l}\text {-tion (non- } \\
\text { shared) }\end{array}$ & \\
\hline $\mathrm{S}$ & $\begin{array}{l}\text { Emotional } \\
\text { exhaustion }\end{array}$ & $0.530 * *$ & $0.417 * *$ & $0.482 * *$ & $0.480 * *$ & $0.222 * *$ \\
\hline \multirow[t]{3}{*}{2} & $\begin{array}{l}\text { Depersonali } \\
\text { zation }\end{array}$ & $0.343 * *$ & $0.378 * *$ & $0.505^{* *}$ & $0.524 * *$ & $0.313 * *$ \\
\hline & $\begin{array}{l}\text { Diminished } \\
\text { personal } \\
\text { accomplish } \\
\text { ment }\end{array}$ & -0.02 & 0.014 & $0.174 * *$ & 0.021 & -0.029 \\
\hline & Total JBS & $0.306 * *$ & $0.288 * *$ & $0.464 * *$ & $0.376^{* *}$ & $0.168 * *$ \\
\hline S & $\begin{array}{l}\text { Depressed } \\
\text { affect }\end{array}$ & $0.400 * *$ & $0.392 * *$ & $0.476^{* *}$ & $0.408 * *$ & $0.251 * *$ \\
\hline \multirow[t]{4}{*}{3} & $\begin{array}{l}\text { Somatic } \\
\text { symptoms }\end{array}$ & $0.438 * *$ & $0.406 * *$ & $0.481 * *$ & $0.409 * *$ & $0.272 * *$ \\
\hline & $\begin{array}{l}\text { Interpersona } \\
1 \text { difficulties }\end{array}$ & $0.178 * *$ & $0.217^{* *}$ & $0.264 * *$ & $0.369 * *$ & $0.291 * *$ \\
\hline & $\begin{array}{l}\text { Negative } \\
\text { affect }\end{array}$ & $0.177 * *$ & $0.292 * *$ & $0.380 * *$ & $0.302 * *$ & $0.191 * *$ \\
\hline & $\begin{array}{l}\text { Total CES- } \\
\text { D }\end{array}$ & $0.426 * *$ & $0.461 * *$ & $0.581 * *$ & $0.503 * *$ & $0.330 * *$ \\
\hline
\end{tabular}


3 Note. St. $=$ Study, Imbalance $=$ Occupational imbalance, Deprivation $=$ Occupational deprivation, 4 Alienation = Occupational alienation, Marginalization = Occupational marginalization, 5 Marginalization (non-shared) = Non-shared environment marginalization, Marginalization $6 \quad($ shared $)=$ Shared environment marginalization. Study 1 is separated 4 factor of CAOD, Study 2 7 and 3 are separated 5 factor of CAOD. 


\section{Table 4(on next page)}

Table 4

Structural relationships of CAOD and SRS-18 
1 Table 4. Structural relationships of CAOD and SRS-18 (study 1)

Estimate S.E. Est./S.E. Two- 95\% CI

TailedP-

Value

Model fit information

RMSEA

$0.061[90 \% \mathrm{CI}=0.057 ; 0.064]$

CFI

0.947

TLI

0.943

\section{Standardized model results}

Stress On

Occupational

dysfunction

$\begin{array}{lllll}0.748 & 0.096 & 7.771 & 0.000 & 0.500 ; 0.995\end{array}$

Covariates

$-0.062$

$0.107 \quad-0.574$

0.566

$-0.338 ; 0.215$

Occupational On

dysfunction

Covariates

0.826

0.026

31.284

0.000

$0.758 ; 0.894$

\section{Occupational by}

dysfunction

Occupational

imbalance

$\begin{array}{lllll}0.677 & 0.028 & 23.861 & 0.000 & 0.604 ; 0.750\end{array}$

Occupational

deprivation

$\begin{array}{lllll}0.893 & 0.017 & 53.737 & 0.000 & 0.850 ; 0.936\end{array}$

Occupational

alienation

0.840

0.021

39.462

0.000

$0.785 ; 0.894$

Occupational

Marginalization

0.880

0.017

52.298

0.000

$0.837 ; 0.923$

Stress by

response

Depression and anxiety
0.971
0.014
70.326
0.000
$0.935 ; 1.006$

Displeasure and anger

$\begin{array}{llllll}0.787 & 0.024 & 32.723 & 0.000 & 0.725 ; & 0.849\end{array}$




\begin{tabular}{lccccc}
\multicolumn{1}{c}{ Lassitude } & 0.915 & 0.017 & 52.651 & 0.000 & $0.870 ; 0.960$ \\
\hline $\begin{array}{l}\text { Covariates Ind } \\
\text { Stress response }\end{array}$ & 0.617 & 0.086 & 7.195 & 0.000 & $0.396 ; 0.838$ \\
\hline $\begin{array}{l}\text { R Square } \\
\text { Stress response }\end{array}$ & 0.487 & 0.040 & 12.112 & 0.000 & - \\
\hline
\end{tabular}

2 Note. S.E. $=$ Standard error, Est. / S.E. $=$ Estimator $/$ Standard error, CI $=$ Confidence interval, 3 On $=$ Structural association, By $=$ Constract, Ind $=$ Indirect, $\mathrm{R}$ Square $=\mathrm{R}$ coefficient of 4 determination 


\section{Table 5(on next page)}

Table 5

Sample characteristics of CAOD and JBS 
1 Table 5. Sample characteristics of CAOD and JBS (study 2)

\begin{tabular}{|c|c|c|c|}
\hline & & \multicolumn{2}{|c|}{$\mathbf{M} \pm \mathbf{S D}$} \\
\hline & Total & \multicolumn{2}{|c|}{$34.5 \pm 10.2$} \\
\hline & Doctors & \multicolumn{2}{|c|}{$48.6 \pm 10.2$} \\
\hline 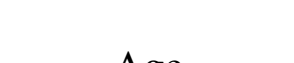 & Nurses & \multicolumn{2}{|c|}{$36.1 \pm 10.5$} \\
\hline Age & Physical therapists & \multicolumn{2}{|c|}{$30.6 \pm 7.3$} \\
\hline & Occupational therapists & \multicolumn{2}{|c|}{$29.6 \pm 6.6$} \\
\hline & Another & \multicolumn{2}{|c|}{$37.2 \pm 11.1$} \\
\hline & Total & \multicolumn{2}{|c|}{$10.5 \pm 9.3$} \\
\hline & Doctors & \multicolumn{2}{|c|}{$23.3 \pm 10.0$} \\
\hline Years of work & Nurses & \multicolumn{2}{|c|}{$12.5 \pm 9.7$} \\
\hline experience & Physical therapists & \multicolumn{2}{|c|}{$7.0 \pm 6.4$} \\
\hline & Occupational therapists & \multicolumn{2}{|c|}{$6.4 \pm 5.7$} \\
\hline & Another & \multicolumn{2}{|c|}{$11.6 \pm 10.5$} \\
\hline & & Total N & $\%$ \\
\hline \multirow{3}{*}{ Gender } & Male & 476 & 41.6 \\
\hline & Female & 650 & 56.9 \\
\hline & Others & 16 & 1.4 \\
\hline \multirow{5}{*}{ Job category } & Doctor & 21 & 1.8 \\
\hline & $\begin{array}{l}\text { Nurse, Health nurse, } \\
\text { Midwife }\end{array}$ & 484 & 42.3 \\
\hline & Physical therapist & 205 & 17.9 \\
\hline & Occupational therapist & 180 & 15.7 \\
\hline & Other healthcare workers & 252 & 22.0 \\
\hline \multirow{6}{*}{$\begin{array}{l}\text { Opportunities } \\
\text { for refreshment }\end{array}$} & Very good & 111 & 9.7 \\
\hline & Good & 629 & 55.0 \\
\hline & Neither good nor bad & 143 & 12.5 \\
\hline & Fair & 112 & 9.8 \\
\hline & Poor & 106 & 9.2 \\
\hline & Unknown & 41 & 3.5 \\
\hline Time spent on & Very good & 82 & 7.1 \\
\hline leisure activities & Good & 509 & 44.5 \\
\hline
\end{tabular}




\begin{tabular}{|c|c|c|c|}
\hline & Neither good nor bad & 33 & 2.8 \\
\hline & Fair & 237 & 20.7 \\
\hline & Poor & 68 & 5.9 \\
\hline & Unknown & 213 & 18.6 \\
\hline \multirow{6}{*}{$\begin{array}{c}\text { Work } \\
\text { relationships }\end{array}$} & Very good & 107 & 9.3 \\
\hline & Good & 463 & 40.5 \\
\hline & Neither good nor bad & 209 & 18.3 \\
\hline & Fair & 48 & 4.2 \\
\hline & Poor & 14 & 1.2 \\
\hline & Unknown & 301 & 26.3 \\
\hline
\end{tabular}

2 


\section{Table 6 (on next page)}

Table 6

Structural relationships CAOD and JBS 
1 Table 6. Structural relationships CAOD and JBS (study 2)

Estimate S.E. Est./S.E. Two- $\quad$ 95\% CI

TailedP-

Value

\section{Model fit information}

RMSEA

$0.076[90 \% \mathrm{CI}=0.073 ; 0.078]$

CFI

0.919

TLI

0.913

\section{Standardized model results}

Burnout On

Occupational

dysfunction

$\begin{array}{lllll}0.876 & 0.060 & 14.714 & 0.000 & 0.723 ; 1.029\end{array}$

Covariates

$\begin{array}{lll}-0.173 & 0.068 & -2.538\end{array}$

0.011

$-0.349 ; 0.003$

Occupational On

dysfunction

\begin{tabular}{llllll} 
Covariates & 0.796 & 0.018 & 45.214 & 0.000 & $0.750 ; 0.841$ \\
\hline $\begin{array}{l}\text { Occupational by } \\
\text { dysfunction } \\
\begin{array}{l}\text { Occupational } \\
\text { imbalance }\end{array}\end{array}$ & 0.714 & 0.017 & 41.649 & 0.000 & $0.670 ; 0.758$ \\
$\begin{array}{l}\text { Occupational } \\
\text { deprivation }\end{array}$ & 0.884 & 0.010 & 86.646 & 0.000 & $0.857 ; 0.910$ \\
$\begin{array}{l}\text { Occupational } \\
\text { alienation }\end{array}$ & 0.855 & 0.012 & 70.107 & 0.000 & $0.824 ; 0.886$ \\
$\begin{array}{l}\text { Occupational } \\
\text { Marginalization } \\
\text { (non shared) }\end{array}$ & 0.888 & 0.011 & 84.104 & 0.000 & $0.861 ; 0.916$ \\
$\begin{array}{l}\text { Occupational } \\
\text { marginalization } \\
\text { (shared) }\end{array}$ & 0.615 & 0.024 & 25.447 & 0.000 & $0.552 ; 0.677$ \\
\hline
\end{tabular}

\section{Burnout by}

syndrome 
Emotional

exhaustion

$\begin{array}{lllll}0.971 & 0.014 & 67.697 & 0.000 & 0.934 ; 1.008\end{array}$

Depersonalizatio

$\mathrm{n}$

$\begin{array}{lllll}0.871 & 0.016 & 55.916 & 0.000 & 0.831 ; 0.911\end{array}$

Diminished

$\begin{array}{lllllll}\text { personal acco- } & 0.178 & 0.032 & 5.642 & 0.000 & 0.097 ; 0.260\end{array}$

mplishment

Covariates Ind

Burnout

syndrome

$\begin{array}{lllll}0.697 & 0.055 & 12.725 & 0.000 & 0.556 ; 0.838\end{array}$

R Square

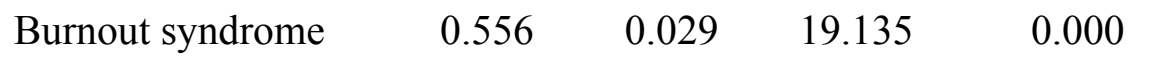

2 Note. S.E. $=$ Standard error, Est. / S.E. $=$ Estimator $/$ Standard error, CI $=$ Confidence interval,

$3 \mathrm{On}=$ Structural association, $\mathrm{By}=$ Constract, Ind $=$ Indirect, $\mathrm{R}$ Square $=\mathrm{R}$ coefficient of

4 determination 


\section{Table 7 (on next page)}

Table 7

Sample characteristics of CAOD and CES-D 
1 Table 7. Sample characteristics of CAOD and CES-D (study 3)

\begin{tabular}{|c|c|c|c|}
\hline & & \multicolumn{2}{|c|}{$\mathbf{M} \pm \mathbf{S D}$} \\
\hline & Total & \multicolumn{2}{|c|}{$33.6 \pm 10.2$} \\
\hline & Nurses & \multicolumn{2}{|c|}{$37.4 \pm 11.2$} \\
\hline Age & Physical therapists & \multicolumn{2}{|c|}{$29.3 \pm 6.4$} \\
\hline & Occupational therapists & \multicolumn{2}{|c|}{$27.6 \pm 4.1$} \\
\hline & Total & \multicolumn{2}{|c|}{$9.67 \pm 9.2$} \\
\hline Years of work & Nurses & \multicolumn{2}{|c|}{$12.8 \pm 10.3$} \\
\hline experience & Physical therapists & \multicolumn{2}{|c|}{$5.64 \pm 5.3$} \\
\hline & Occupational therapists & \multicolumn{2}{|c|}{$4.84 \pm 3.5$} \\
\hline & & Total N & $\%$ \\
\hline \multirow{3}{*}{ Gender } & Male & 159 & 23.5 \\
\hline & Female & 509 & 75.4 \\
\hline & Unknown & 7 & 1.0 \\
\hline \multirow{6}{*}{ Job category } & Nurse & 326 & 48.2 \\
\hline & Health nurse, Midwife & 12 & 1.7 \\
\hline & Assistant nurse & 63 & 9.3 \\
\hline & Physical therapist & 155 & 22.9 \\
\hline & Occupational therapist & 123 & 18.2 \\
\hline & Unknown & 8 & 1.1 \\
\hline \multirow{6}{*}{$\begin{array}{l}\text { Opportunities } \\
\text { for refreshment }\end{array}$} & Very good & 71 & 10.5 \\
\hline & Good & 364 & 54 \\
\hline & Neither good nor bad & 91 & 13.5 \\
\hline & Fair & 56 & 8.3 \\
\hline & Poor & 62 & 9.1 \\
\hline & Unknown & 30 & 4.4 \\
\hline \multirow{6}{*}{$\begin{array}{c}\text { Time spent on } \\
\text { leisure activities }\end{array}$} & Very good & 53 & 7.8 \\
\hline & Good & 285 & 42.2 \\
\hline & Neither good nor bad & 141 & 20.9 \\
\hline & Fair & 123 & 18.2 \\
\hline & Poor & 43 & 6.3 \\
\hline & Unknown & 29 & 4.3 \\
\hline
\end{tabular}




\begin{tabular}{clcc}
\hline & Very good & 85 & 12.6 \\
& Good & 356 & 52.8 \\
Work & Neither good nor bad & 162 & 24 \\
relationships & Fair & 29 & 4.3 \\
& Poor & 13 & 1.9 \\
& Unknown & 29 & 4.3 \\
\hline
\end{tabular}

2 


\section{Table 8 (on next page)}

Table 8

Structural relationships CAOD and CES-D 
1 Table 8. Structural relationships CAOD and CES-D (study 3)

$\begin{array}{llll}\text { Estimate } & \text { S.E. } & \text { Est./S.E. Two- } & \text { T5\% CI }\end{array}$

TailedP-

Value

Model fit information

RMSEA

$0.060[90 \% \mathrm{CI}=0.057 ; 0.063]$

CFI

0.922

TLI

0.917

\section{Standardized model results}

Depression On

Occupational

dysfunction

$\begin{array}{lllll}0.695 & 0.067 & 10.301 & 0.000 & 0.521 ; 0.869\end{array}$

Covariates

$\begin{array}{lll}0.063 & 0.076 & 0.829\end{array}$

0.407

$-0.133 ; 0.259$

Occupational On

dysfunction

\begin{tabular}{|c|c|c|c|c|c|}
\hline Covariates & 0.783 & 0.023 & 33.791 & 0.000 & $0.723 ; 0.842$ \\
\hline \multicolumn{6}{|l|}{$\begin{array}{l}\text { Occupational } \\
\text { dysfunction }\end{array}$} \\
\hline $\begin{array}{l}\text { Occupational } \\
\text { imbalance }\end{array}$ & 0.688 & 0.025 & 27.477 & 0.000 & $0.624 ; 0.753$ \\
\hline $\begin{array}{l}\text { Occupational } \\
\text { deprivation }\end{array}$ & 0.898 & 0.015 & 57.989 & 0.000 & $0.858 ; 0.938$ \\
\hline $\begin{array}{l}\text { Occupational } \\
\text { alienation }\end{array}$ & 0.874 & 0.015 & 56.918 & 0.000 & $0.835 ; 0.914$ \\
\hline \multicolumn{6}{|l|}{ Occupational } \\
\hline $\begin{array}{l}\text { Marginalization } \\
\text { (non shared) }\end{array}$ & 0.879 & 0.014 & 61.800 & 0.000 & $0.843 ; 0.916$ \\
\hline $\begin{array}{l}\text { Occupational } \\
\text { marginalization } \\
\text { (shared) }\end{array}$ & 0.632 & 0.032 & 19.721 & 0.000 & $0.549 ; 0.714$ \\
\hline \multicolumn{6}{|l|}{ Depression by } \\
\hline Depressed affect & 0.960 & 0.015 & 65.960 & 0.000 & $0.922 ; 0.997$ \\
\hline
\end{tabular}




\begin{tabular}{lccccc}
$\begin{array}{l}\text { Somatic } \\
\text { symptoms }\end{array}$ & 0.915 & 0.017 & 54.215 & 0.000 & $0.872 ; 0.959$ \\
$\begin{array}{l}\text { Interpersonal } \\
\text { difficulties }\end{array}$ & 0.785 & 0.032 & 24.395 & 0.000 & $0.702 ; 0.868$ \\
$\quad \begin{array}{l}\text { Negative affect } \\
\text { ind }\end{array}$ & 0.543 & 0.041 & 13.098 & 0.000 & $0.436 ; 0.649$ \\
\hline $\begin{array}{l}\text { Covariates } \\
\text { Depression }\end{array}$ & 0.544 & 0.057 & 9.578 & 0.000 & $0.398 ; 0.690$ \\
\hline $\begin{array}{l}\text { R Square } \\
\text { Depression }\end{array}$ & 0.556 & 0.031 & 17.714 & 0.000 & - \\
\hline
\end{tabular}

2 Note. S.E. $=$ Standard error, Est. $/$ S.E. $=$ Estimator $/$ Standard error, CI $=$ Confidence interval, 3 On $=$ Structural association, By $=$ Constract, Ind $=$ Indirect, $\mathrm{R}$ Square $=\mathrm{R}$ coefficient of 4 determination 